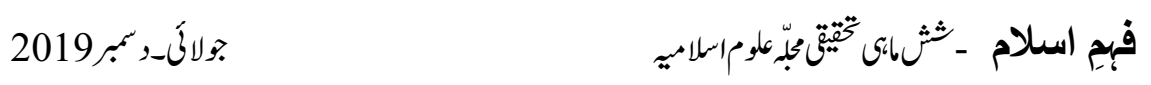

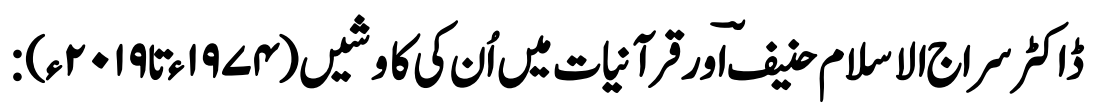

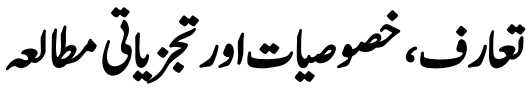

\section{Dr. Siraj-ul-Islam Hanief and his Quranic Contributions (1981-2019): An Analytical Study}

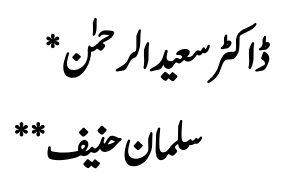

\begin{abstract}
The Noble Quran is the central Islamic divine text and a complete code of life. For better understanding of the Quran, Mufassireen and other Muslim Scholars have been engaged in writing Tafasir \& books on its explanation and interpretations. Dr Siraj-ul-Islam Hanief is an Islamic Scholar, hailing from a remote but historical area named Hussai located near Shabaz Ghari in Mardan district of KP. In Islamic Studies, his speciality (interest) is in Tafsir and Hadith, specifically Fan "Asma-Al-Rijal" and "Jarh-Wa-Tadeel". He has authored about 60 books in Arabic, Urdu \& Pashto languages on Tafsir, Hadith, Aqidaha, Fiqh and various other toipcs. Out of which 40 books have been published uptill now. Besides this he has supervised many research scholars who worked on Tafsir projects. He has also been delivering annual Dwra-e-Tafsir at Masjid Taqwa, Hussai. Dr Siraj has been serving as Theology \& Arabic Teacher, Lecturer and Assistant Professor of Islamic Studies in the education department, colleges \& universities of the Khyber Pakhtunkhwa from time to time. Though, Dr Siraj-ulIslam's Islamic scholarship and authorship and contribution in the field of Quran and its sciences, are of paramount importance but unfortunately very little number of people from academia know about it. This paper presents a scholarly and analytical study of his contributions (Books, Articles, Duroos, Research Supervisions and Projects) in Quranic Studies (1974-2019) for the information, easy access and facilitation of research scholars in Islamic Studies.
\end{abstract}

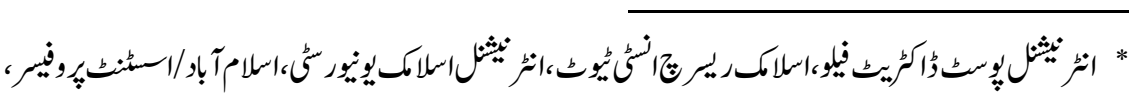

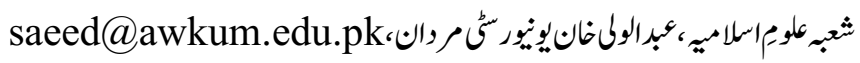

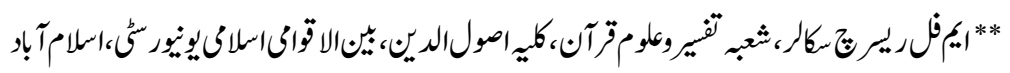


Key Words: Siraj-ul-Islam, Hanief, Dar Al-Quran Wa Sunnah, Hussai, Mardan, Tafsir, Talkhees, Uloom Al-Quran

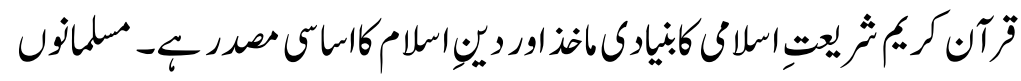

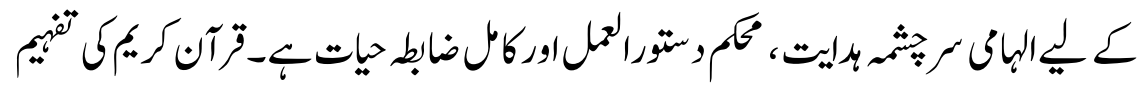

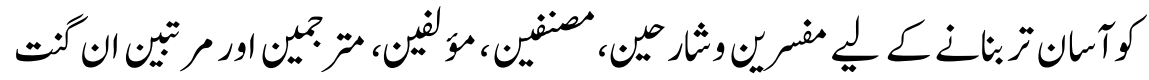

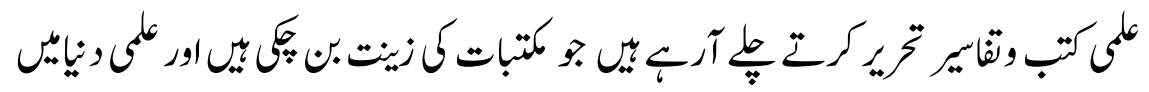

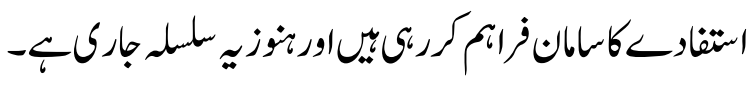

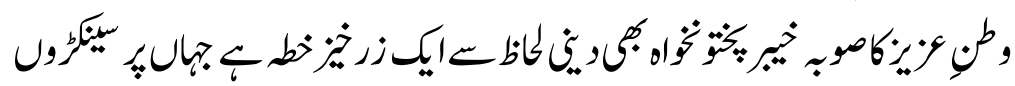

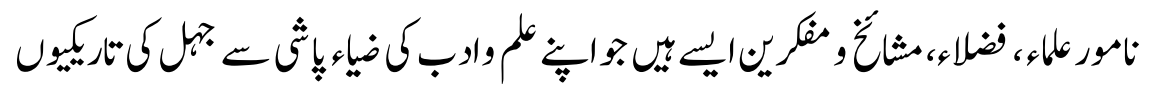

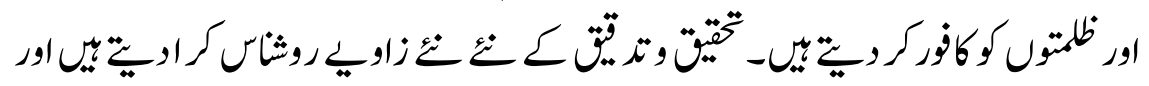

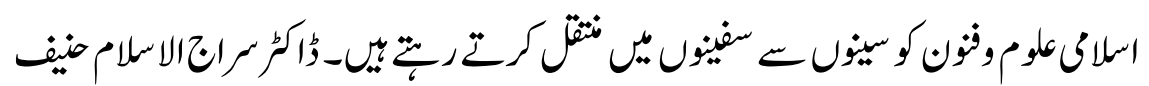

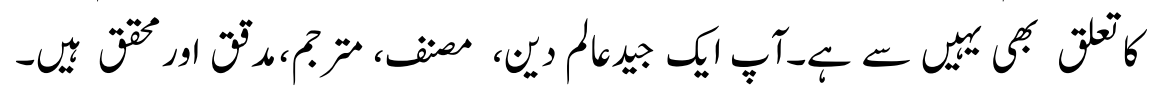

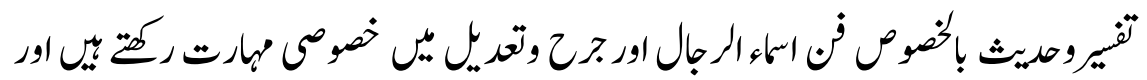

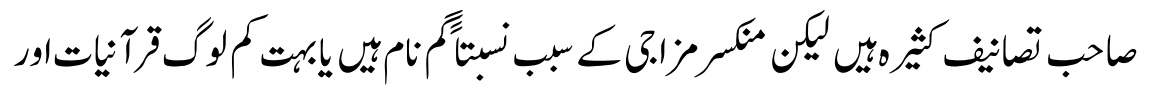

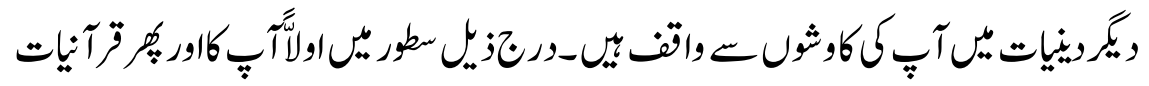

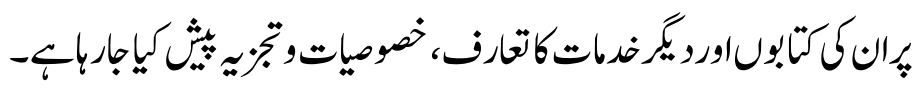

\section{ولاوت،سلمل نب،كنيت،قب،،لا قأكنام}

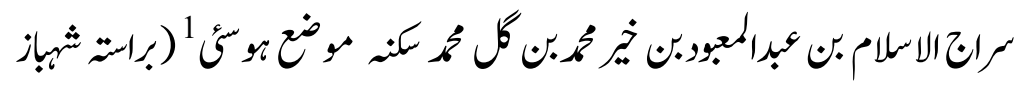

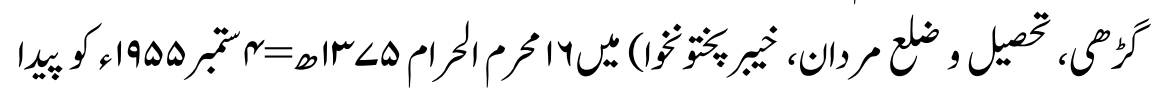

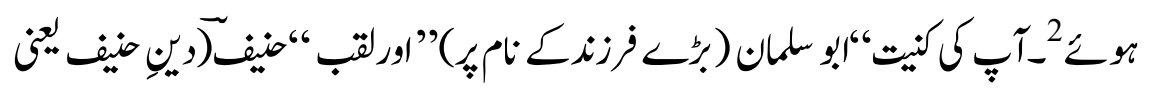

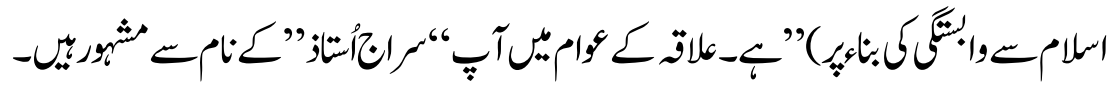




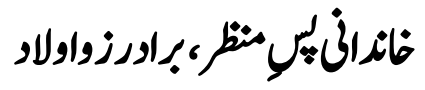

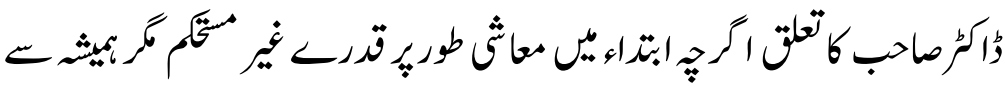

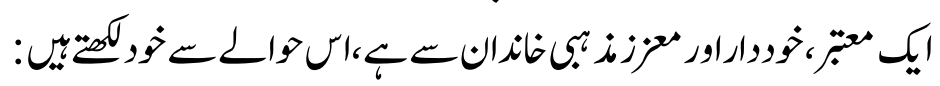

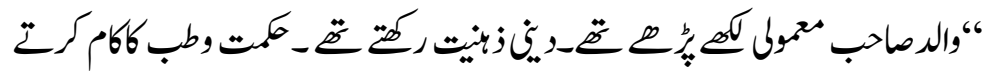

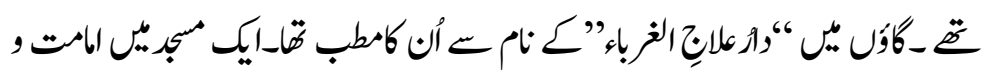

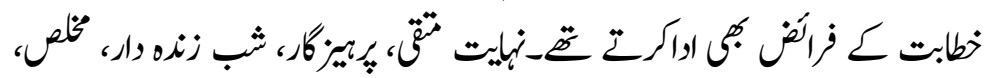

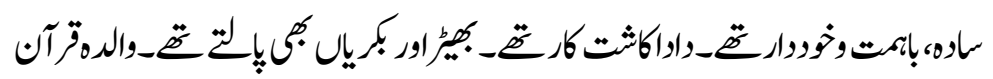

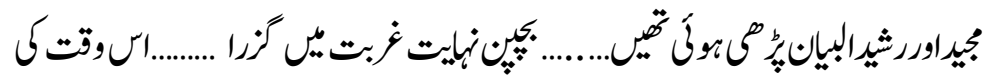

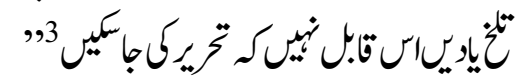

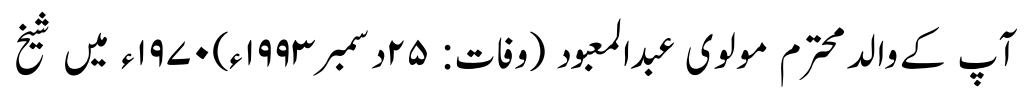

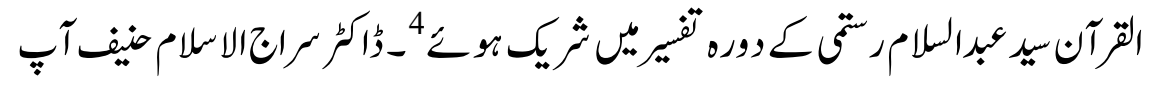

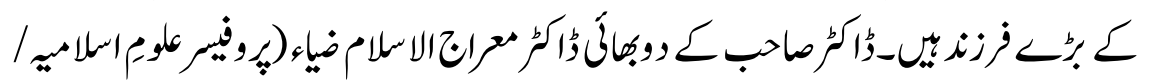

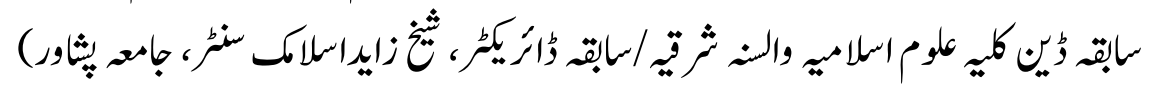

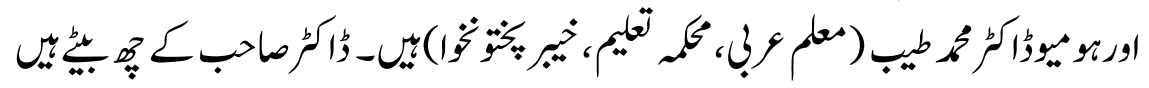

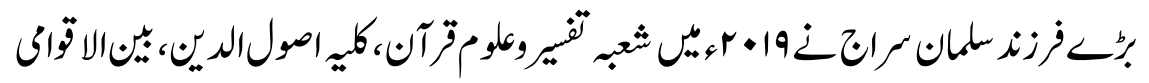

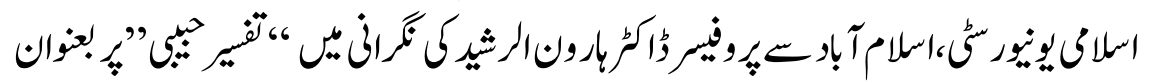

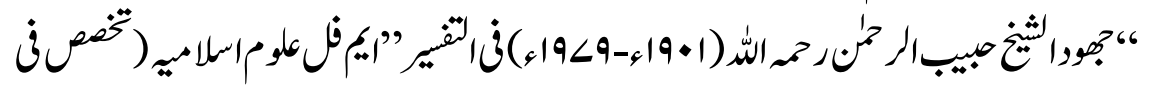

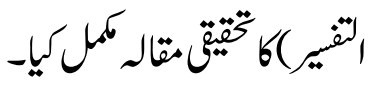

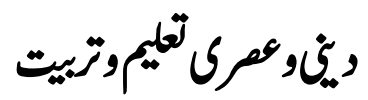

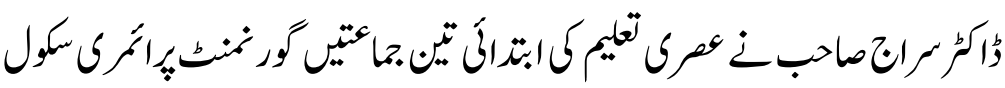

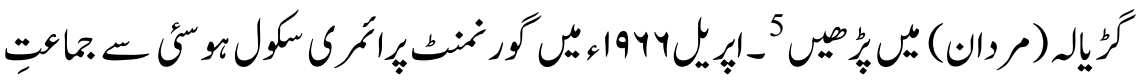

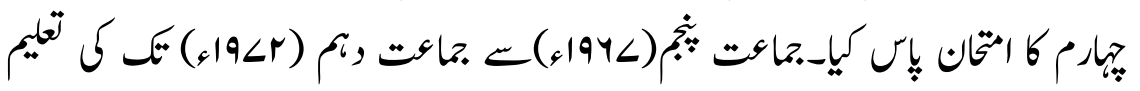




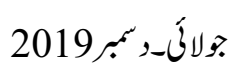

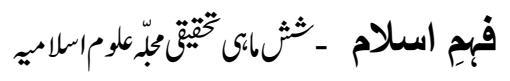

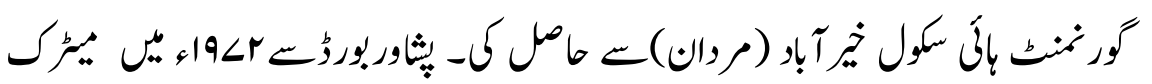

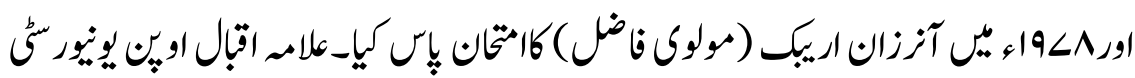

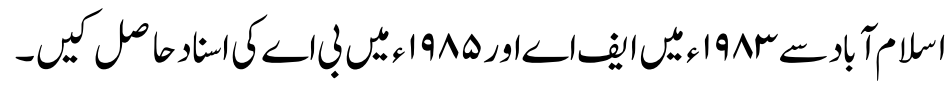

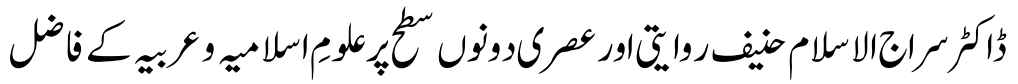

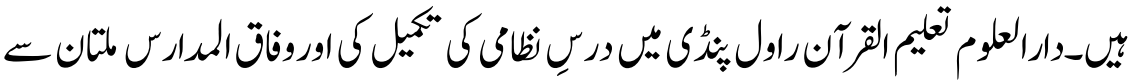

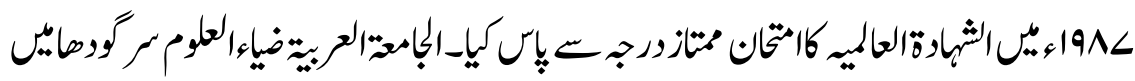

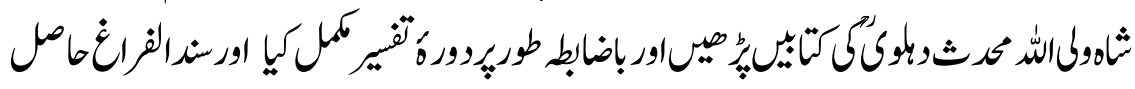

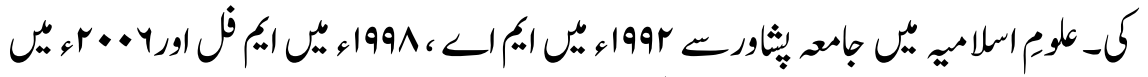

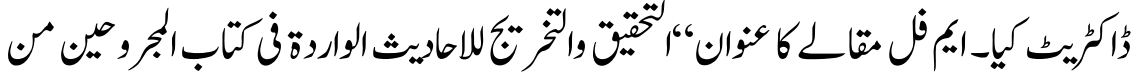

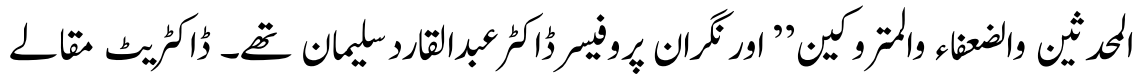

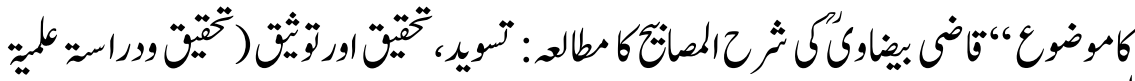

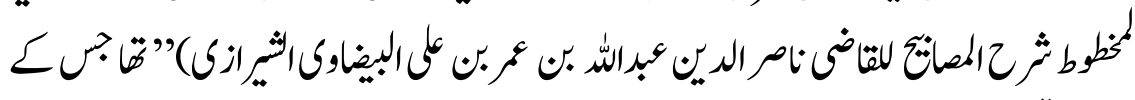

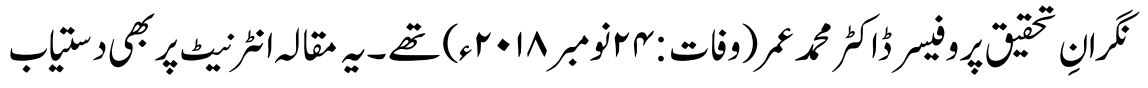

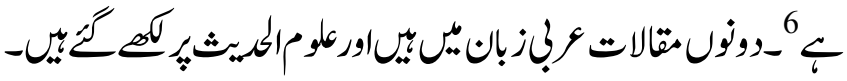

ناموراساته

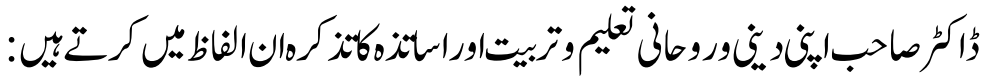

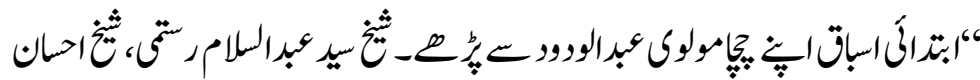

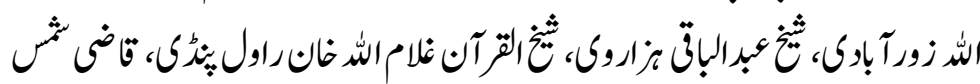

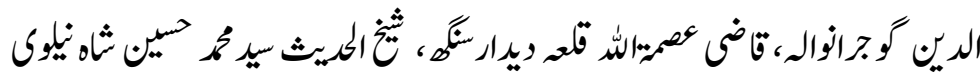

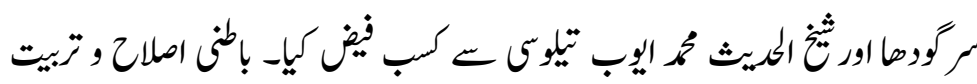

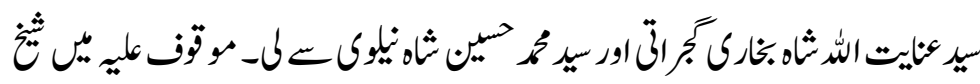

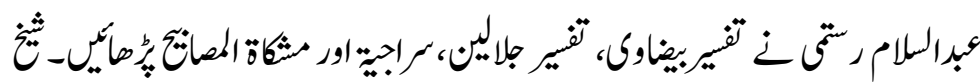

4 
جولأَــ كبر2019

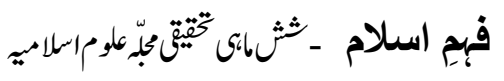

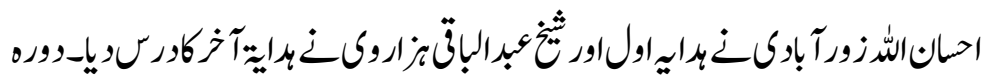

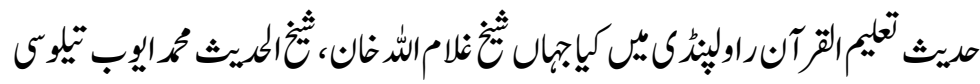

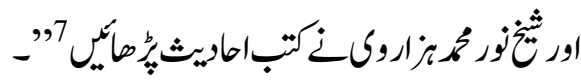

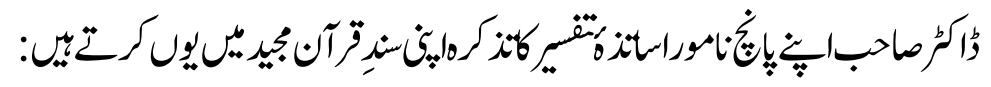

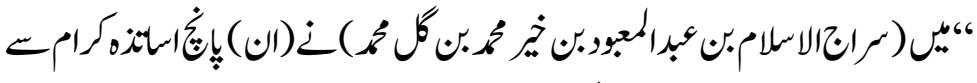

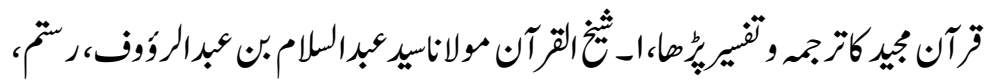

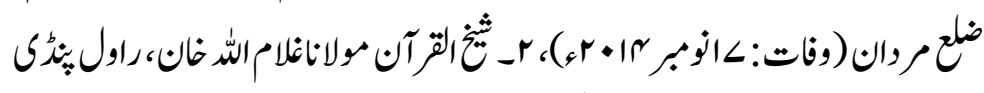

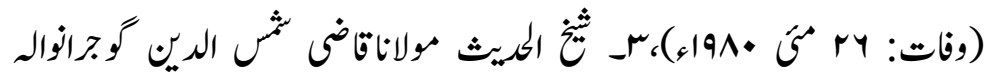

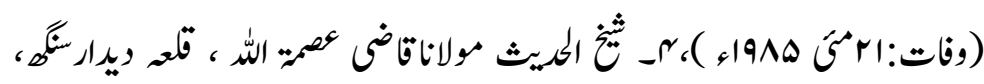

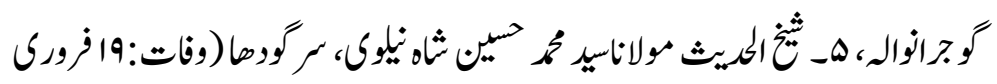
- $88+. .04$

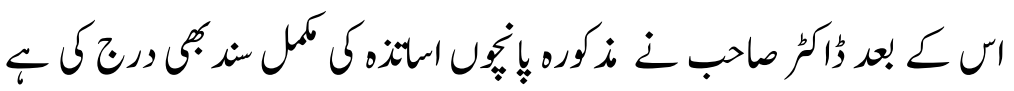

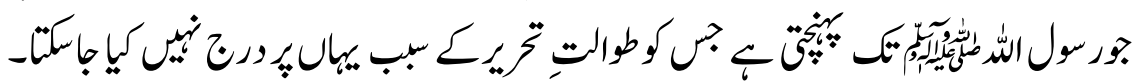

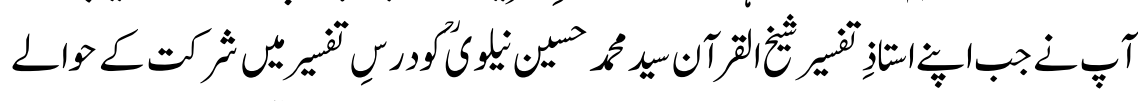

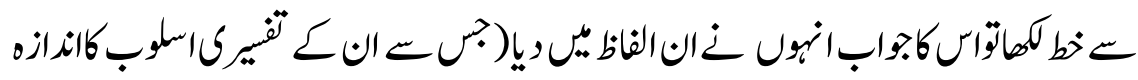

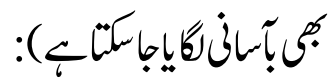

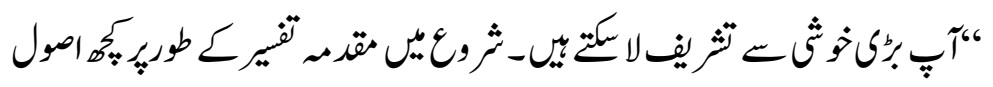

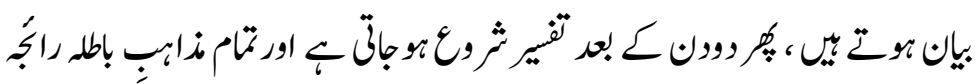

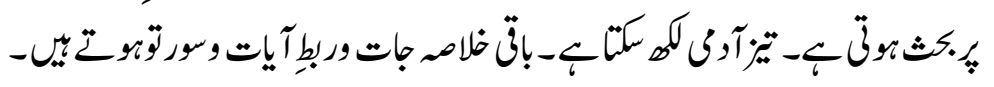

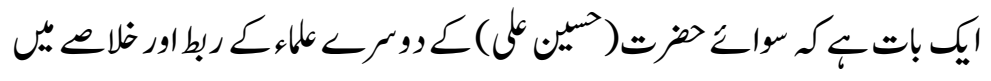

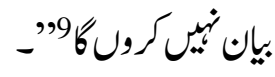

5 


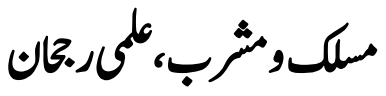

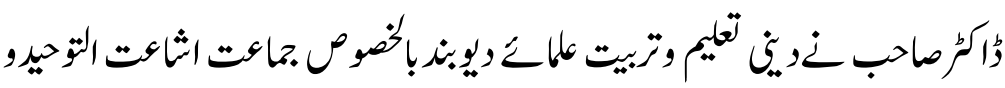

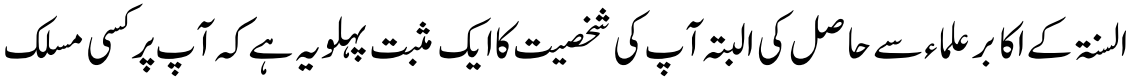

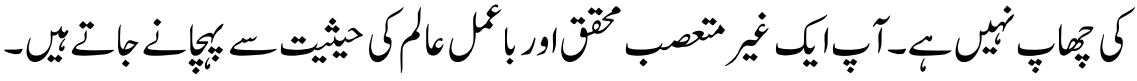

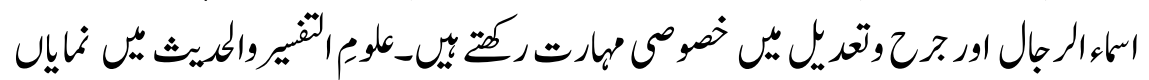

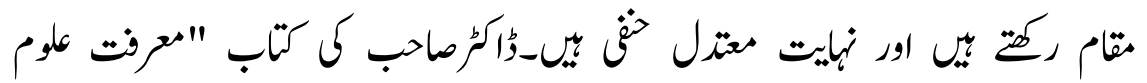

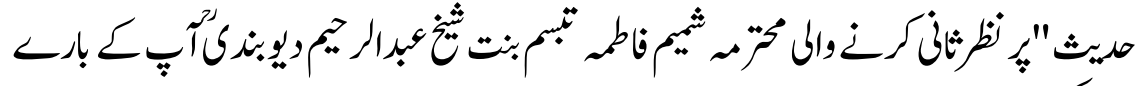

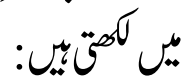

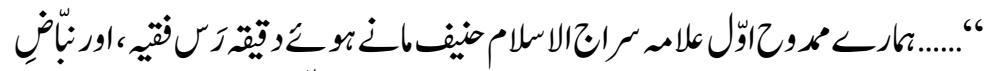

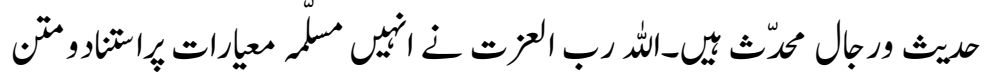

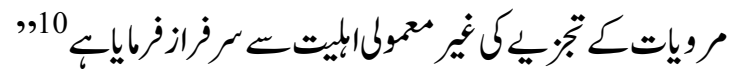

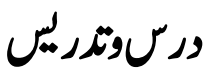

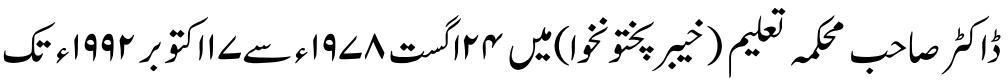

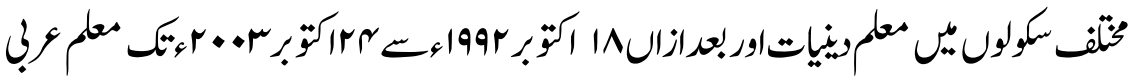

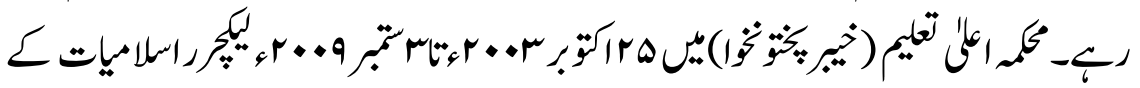

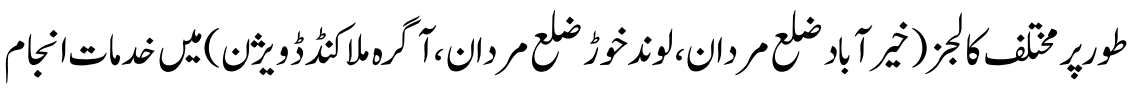

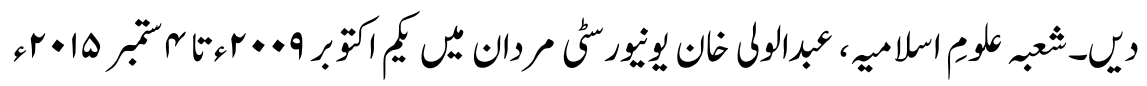

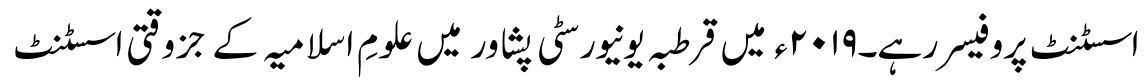

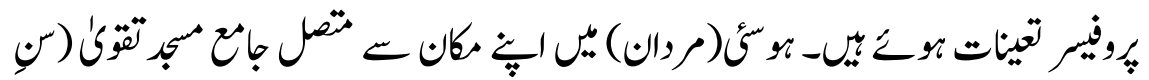

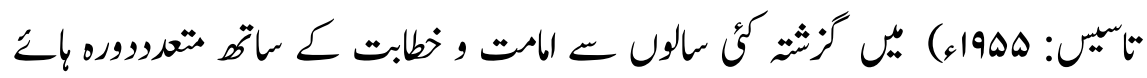

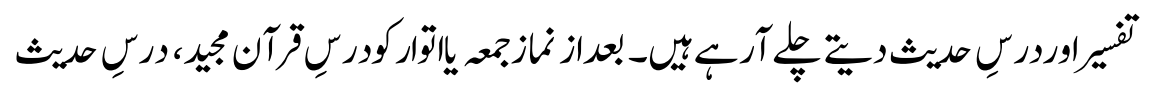




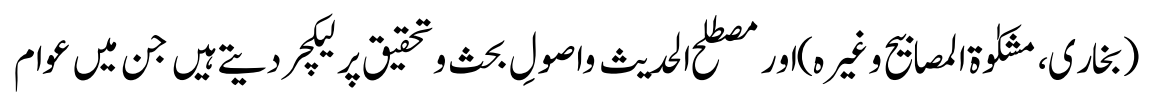

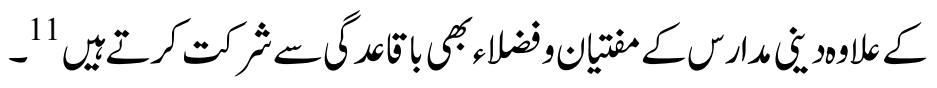

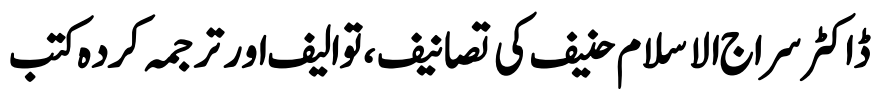

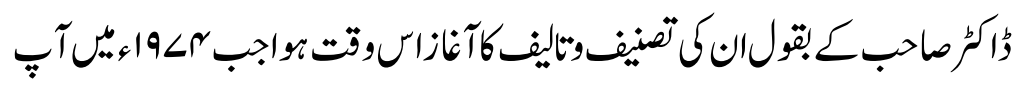

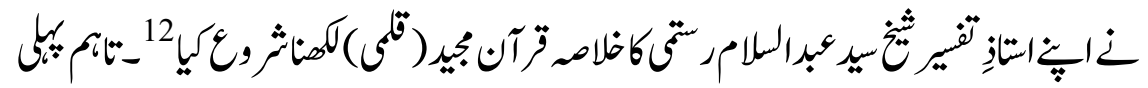

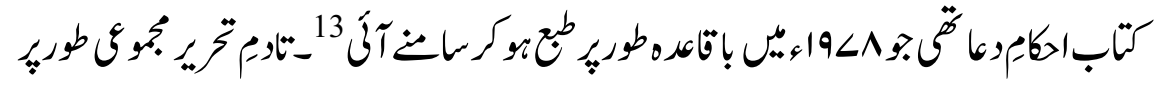

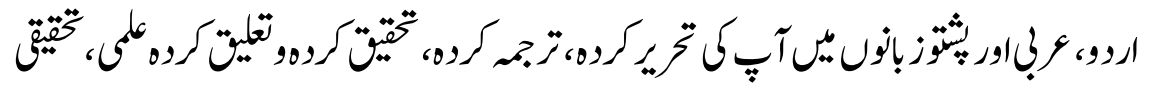

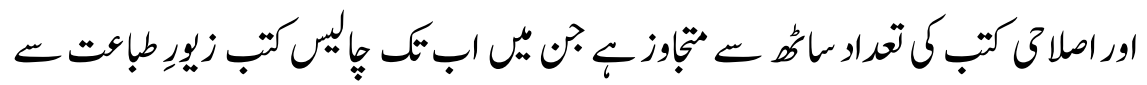

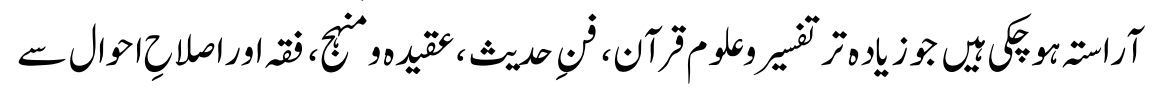

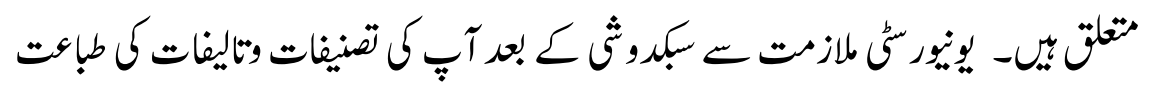

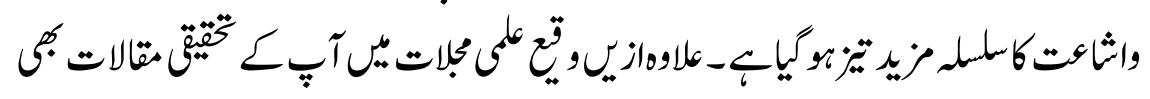

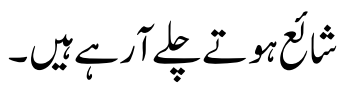

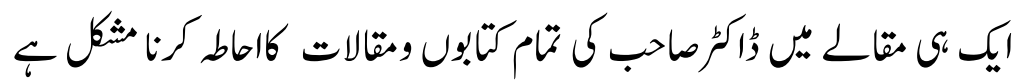

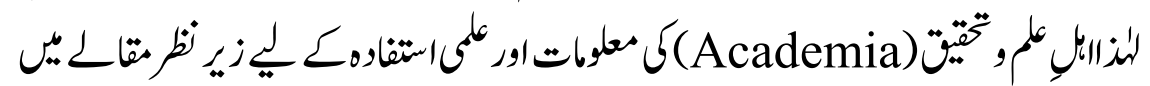

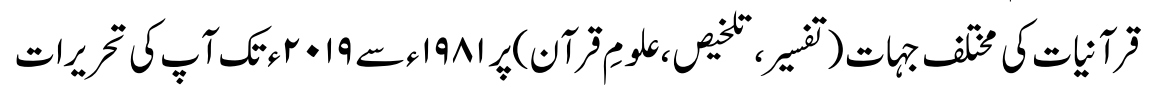

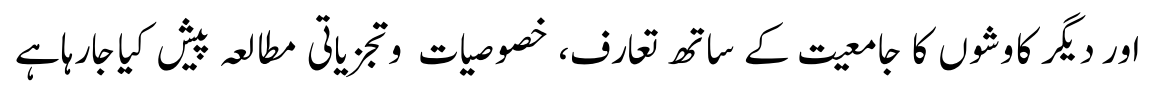

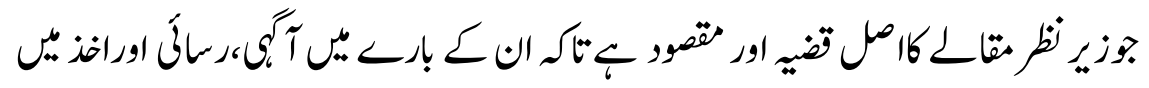

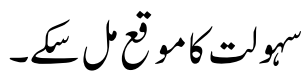




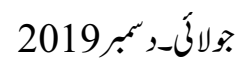

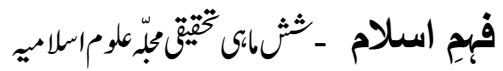

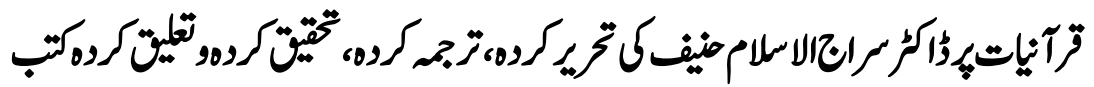

\begin{tabular}{|c|c|c|c|}
\hline زبان & صنات & 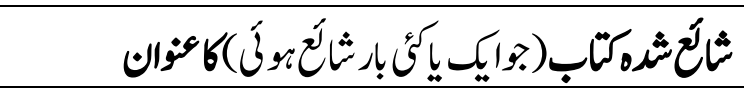 & 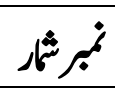 \\
\hline ث: & IIrN & 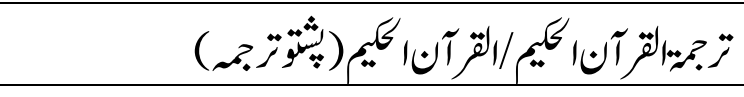 & $(1$ \\
\hline أرُو & $9 \cdot$. & علومالتَ آن [مجلدوليّ] & (2 \\
\hline أرُو & IrAT & 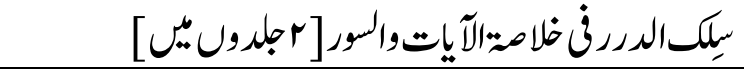 & (3) \\
\hline أرُرو & rir & 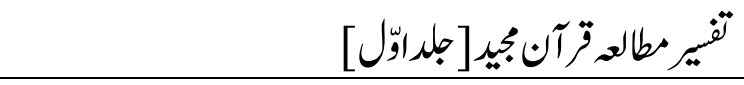 & $(4$ \\
\hline أرُرو & ryr & منأعجالمغرين & $(5$ \\
\hline وبجٍ & $\Delta<\cdot$ & 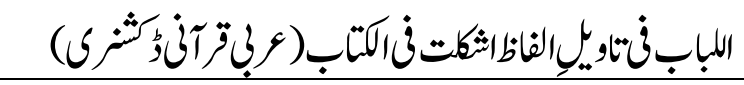 & $(6$ \\
\hline أرُرو & 441 & 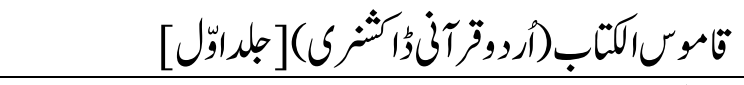 & $(7$ \\
\hline وبق & 101 & 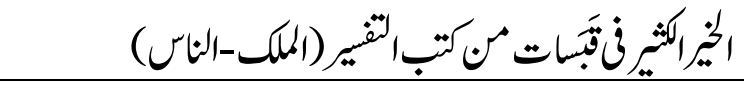 & $(8$ \\
\hline 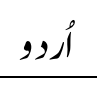 & r & 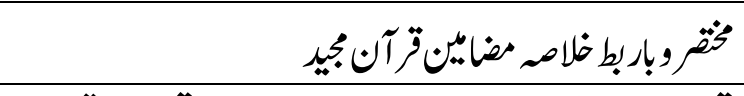 & $(9$ \\
\hline أرُرو & IIIY & 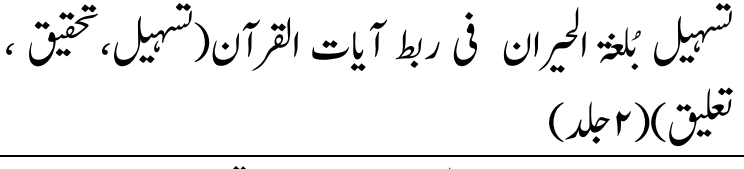 & $(10$ \\
\hline 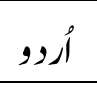 & $\angle \cdot \cdot$ & 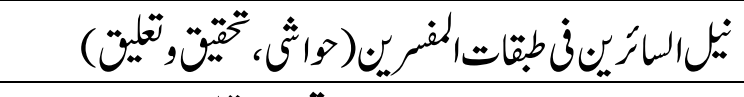 & $(11$ \\
\hline أرُو, & a. & 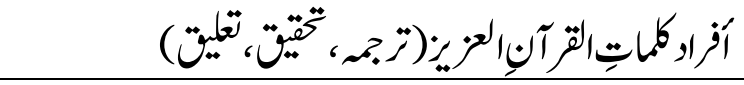 & $(12$ \\
\hline
\end{tabular}

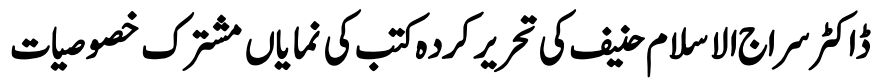

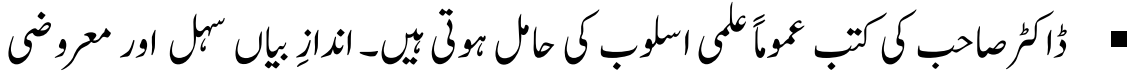
$-4+6$

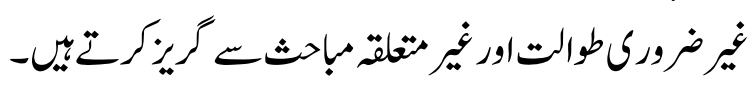

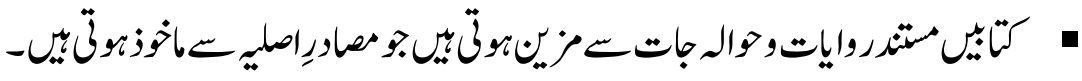

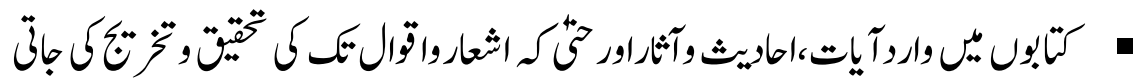




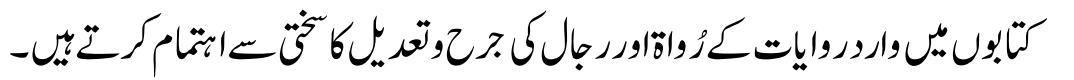

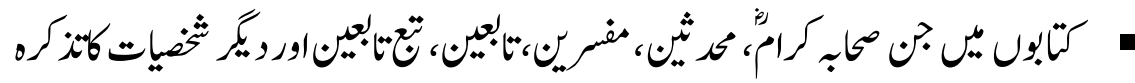

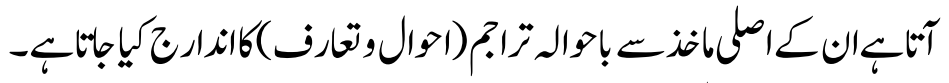

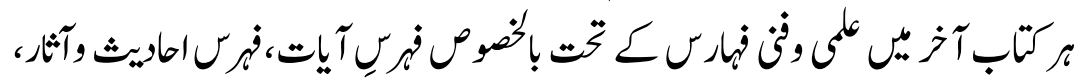

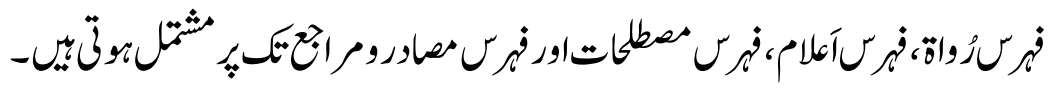

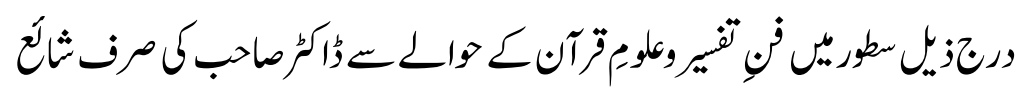

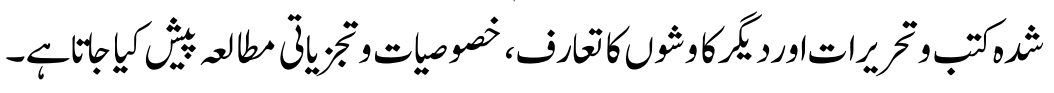

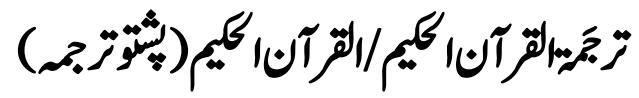

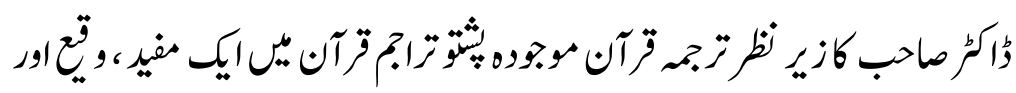

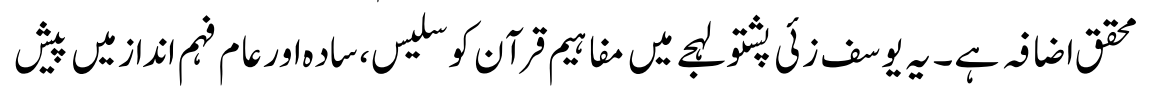

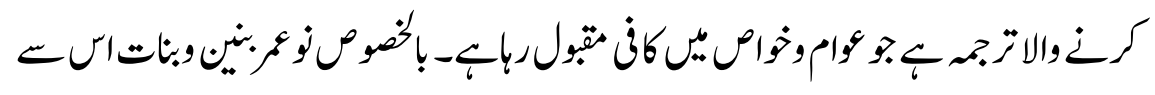

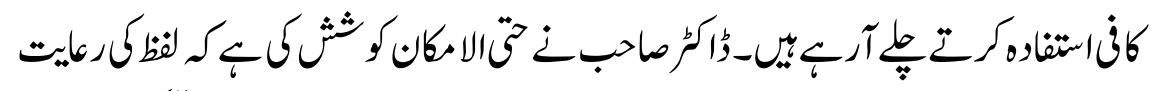

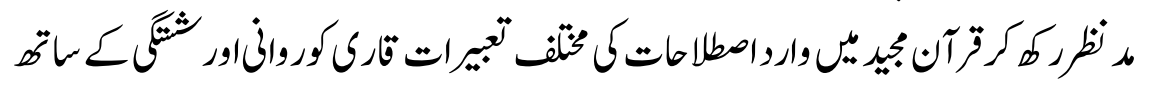

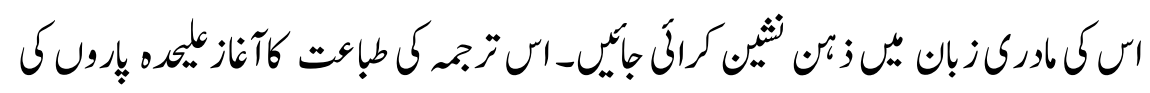

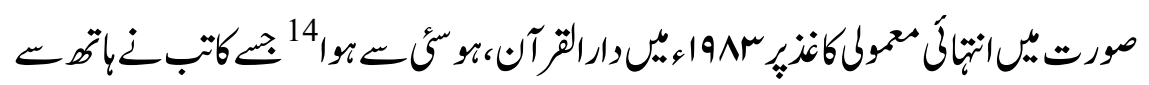

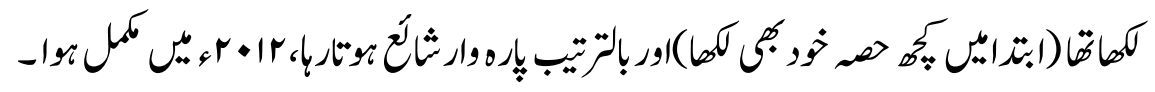

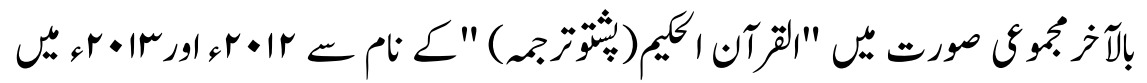

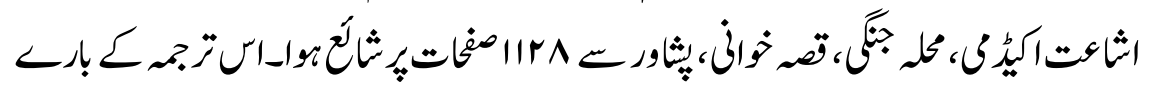

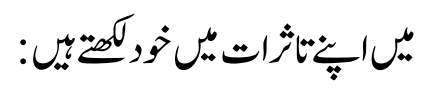

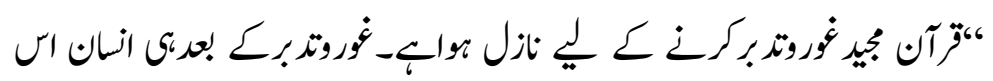

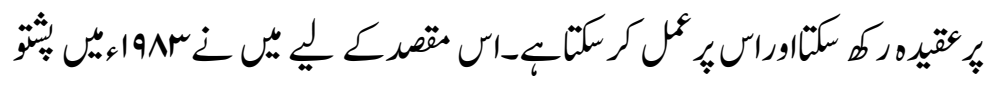


جولأَــ بمبر2019

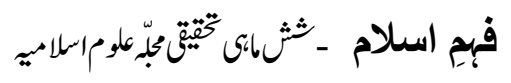

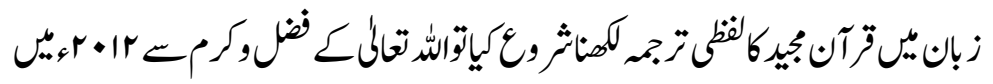

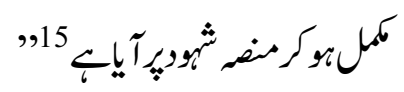

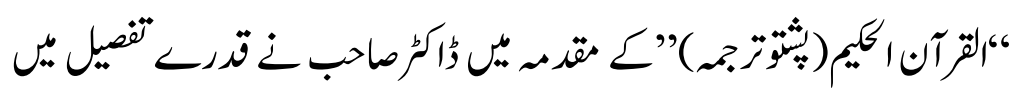

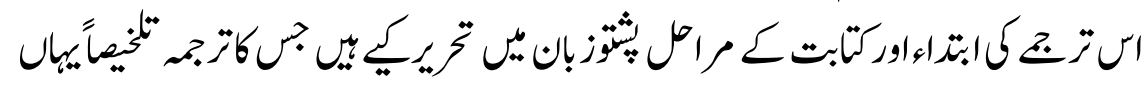

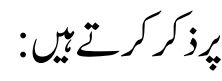

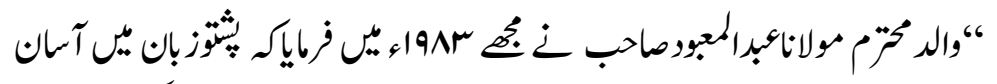

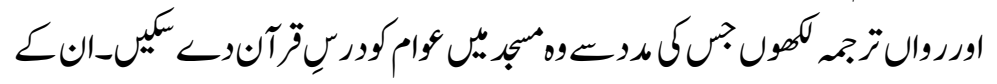

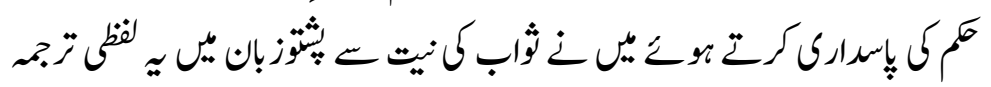

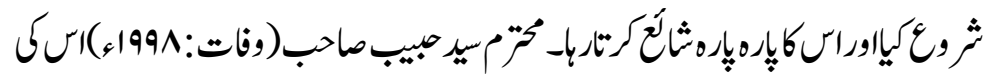

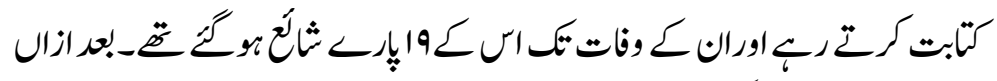

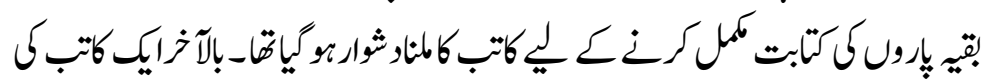

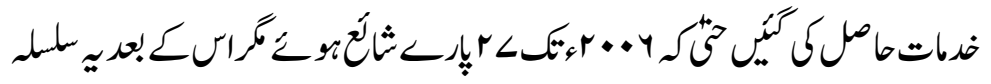

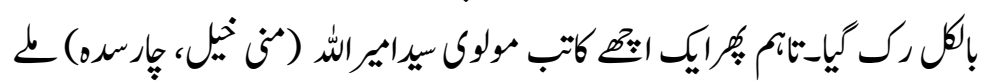

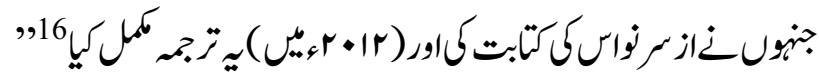

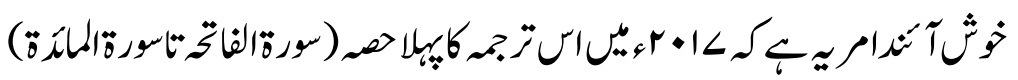

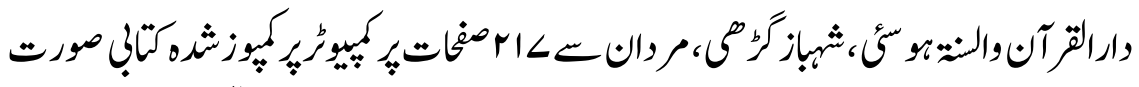

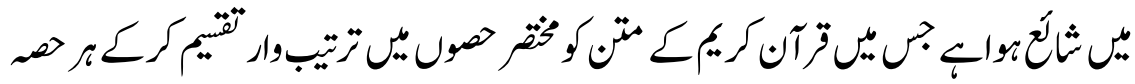

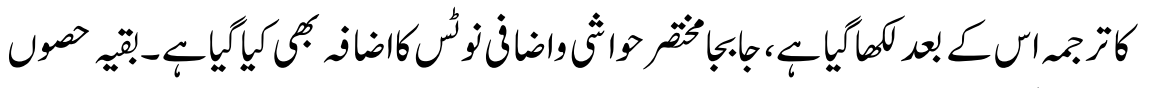

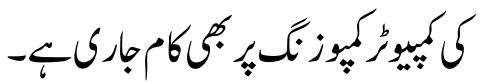

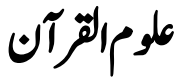

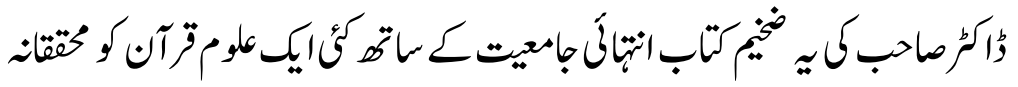

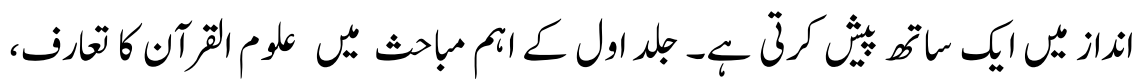

10 


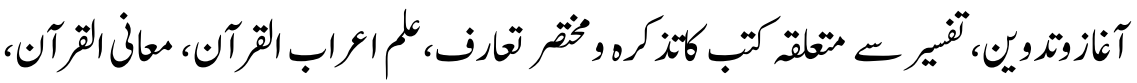

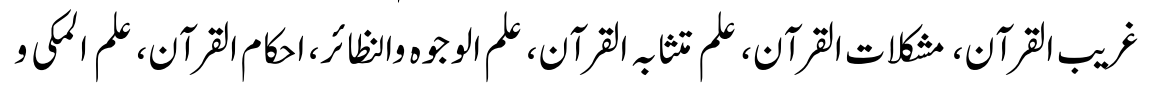

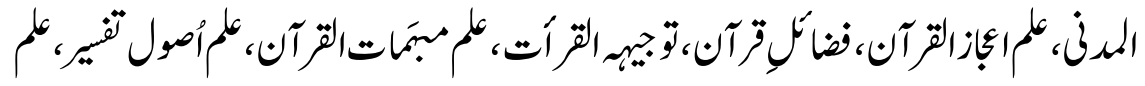

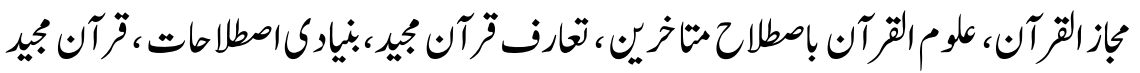

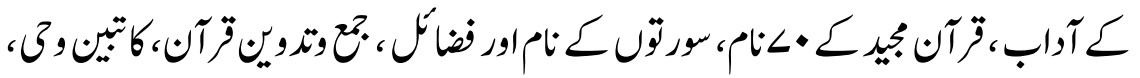

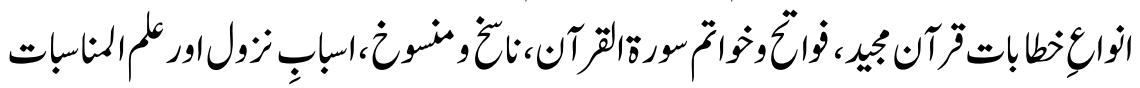

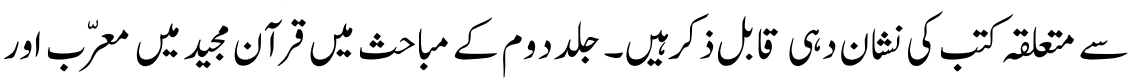

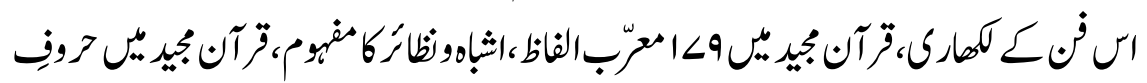

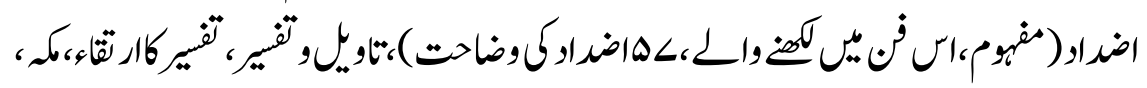

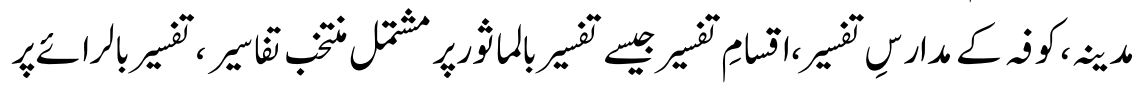

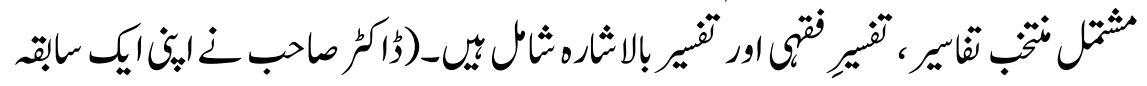

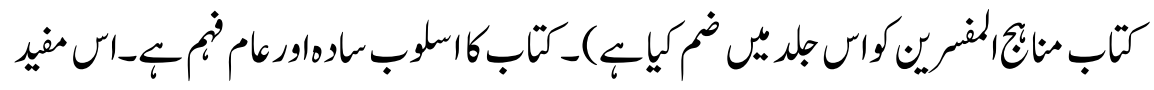

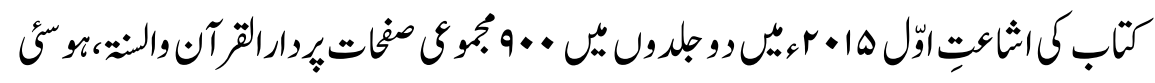

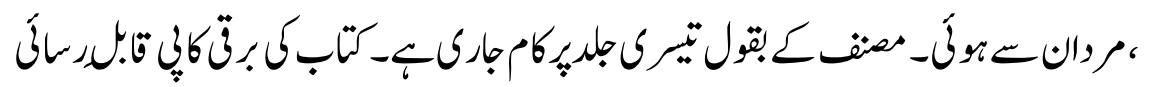

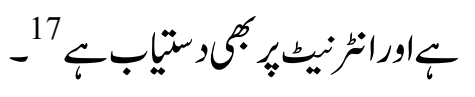

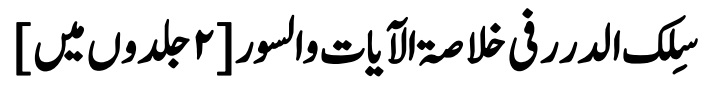

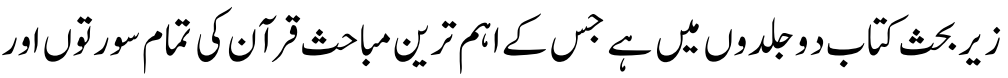

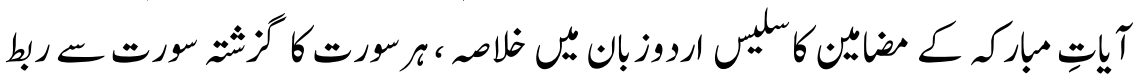

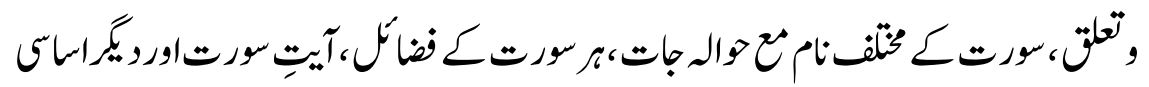

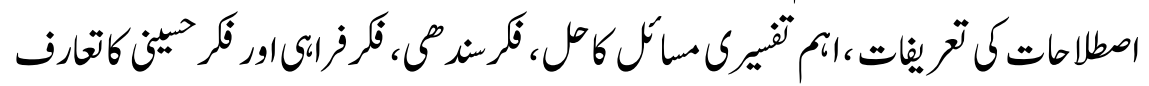

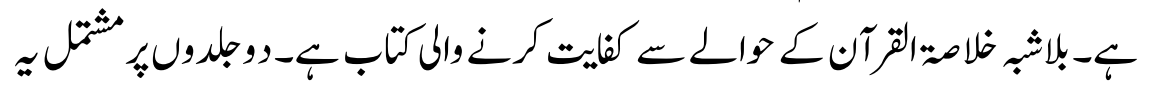

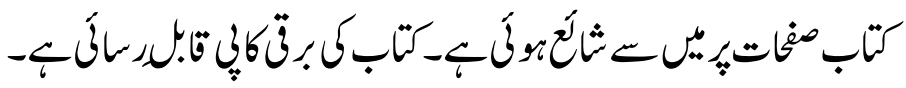




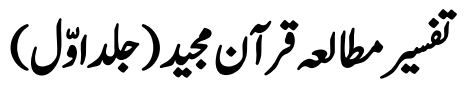

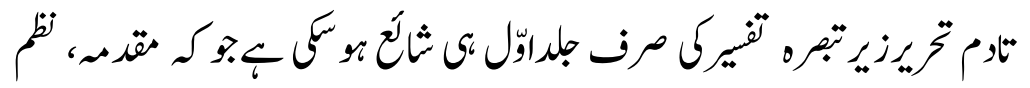

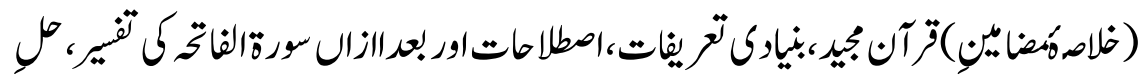

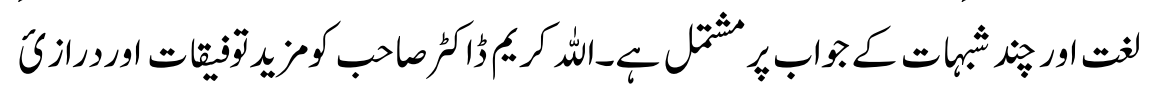

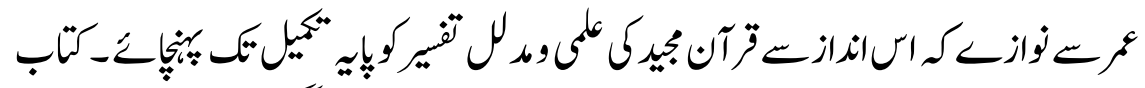

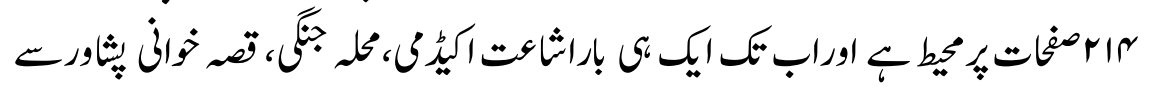
-

\section{مناعج المفمركن}

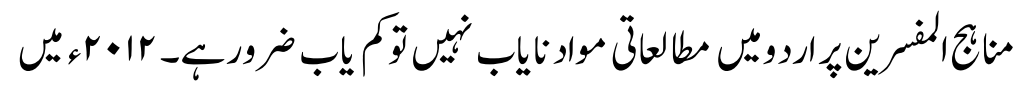

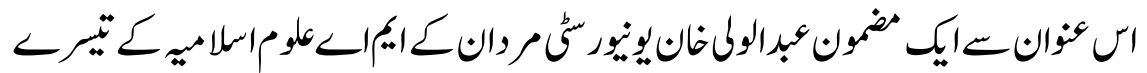

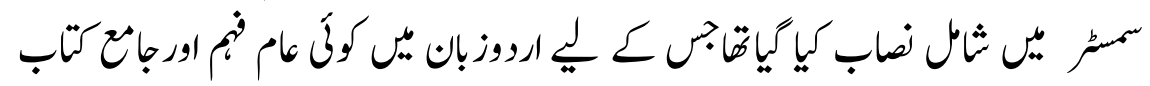

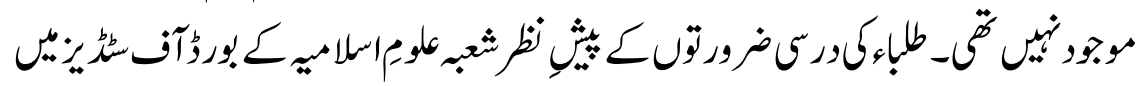

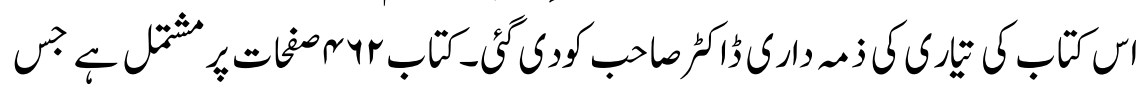

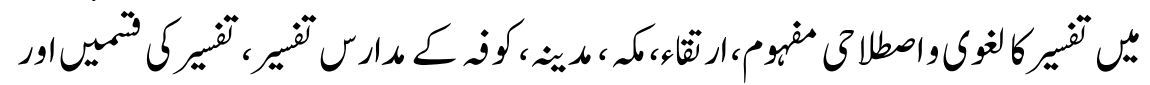

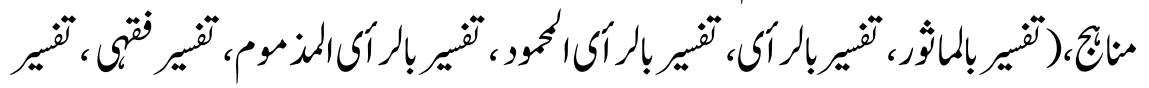

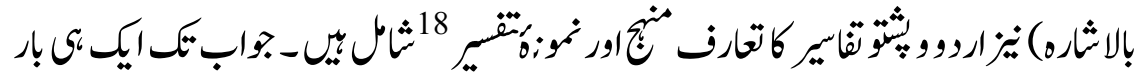

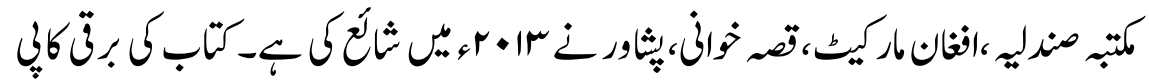

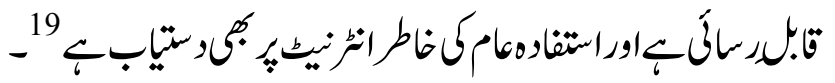

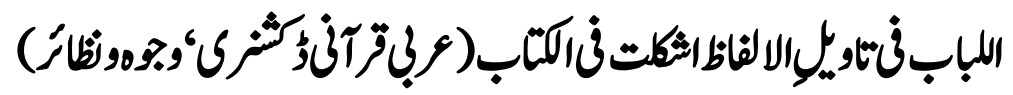

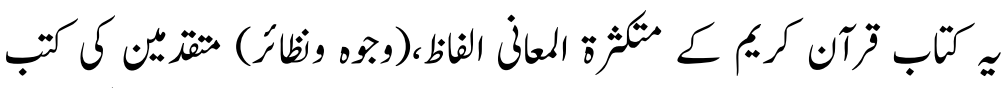

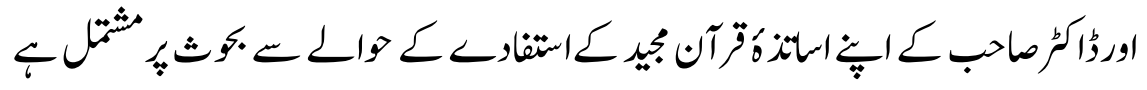




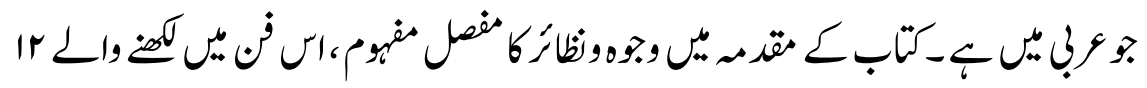

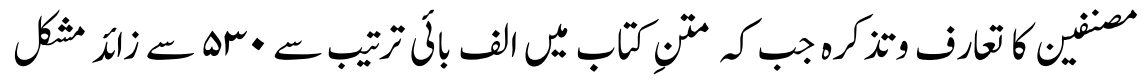

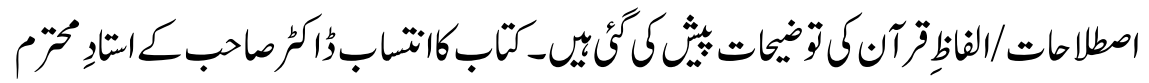

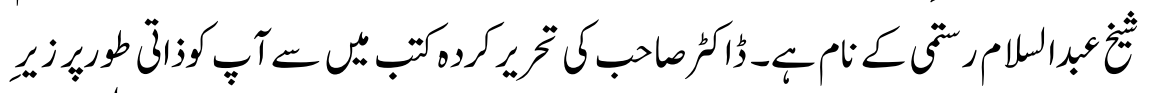

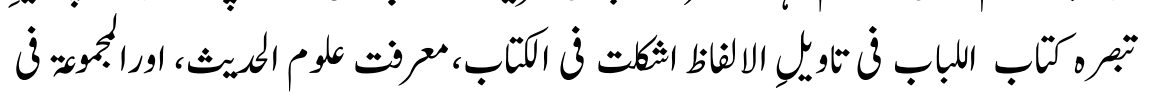

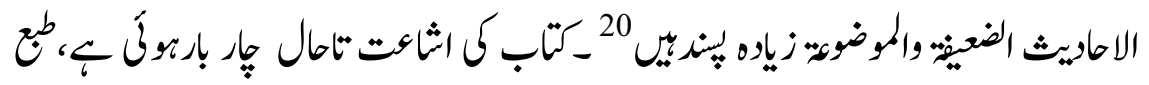

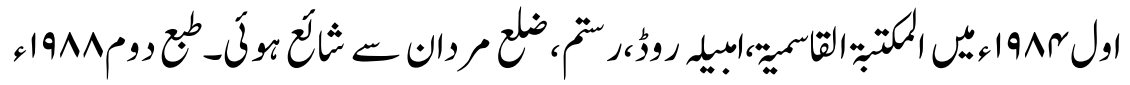

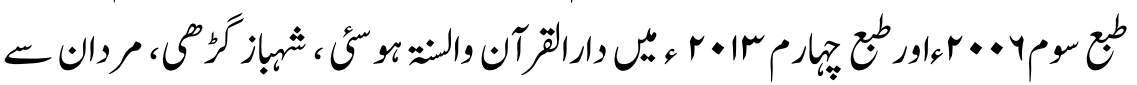

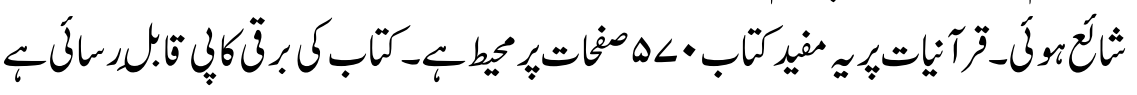

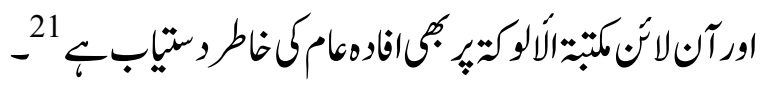

\section{قاموساكتب(ارووز آذأكثرى)}

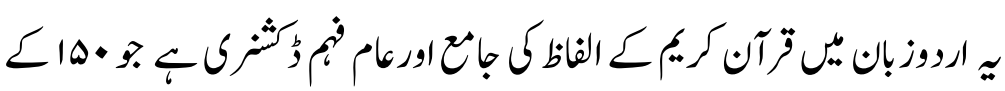

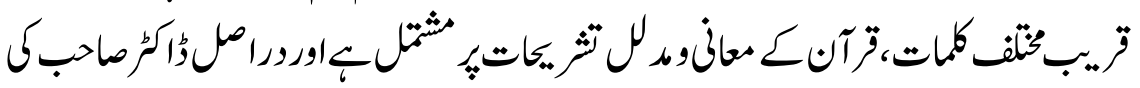

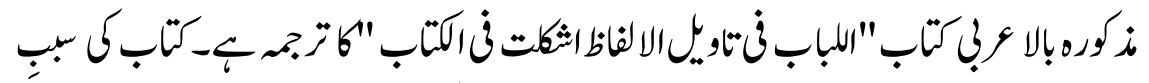

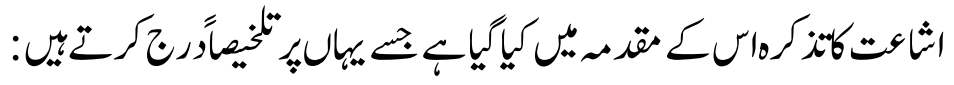

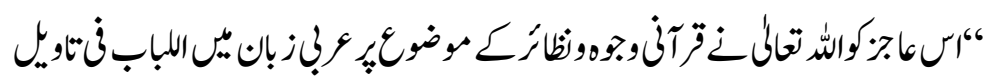

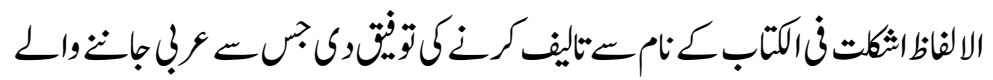

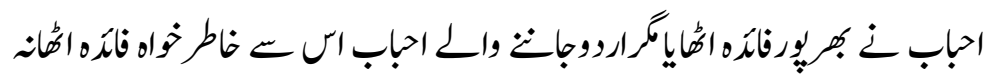

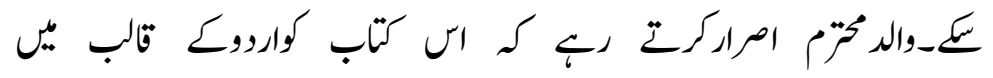

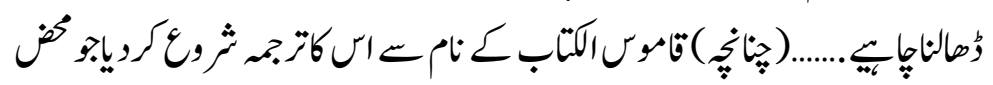

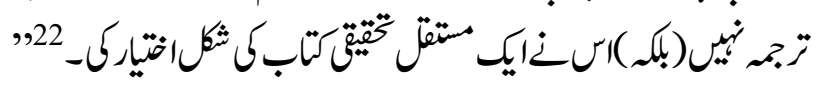




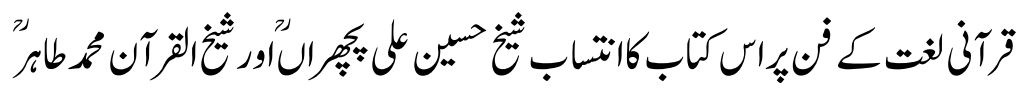

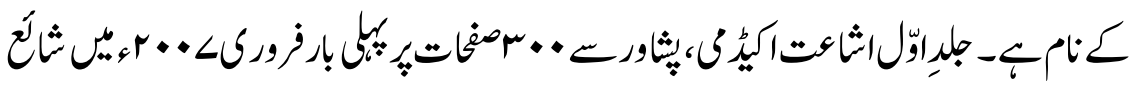

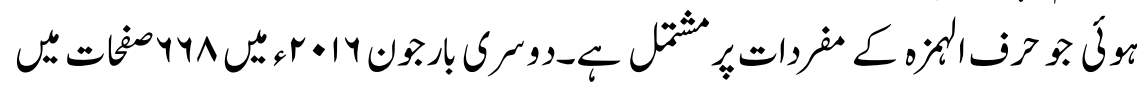

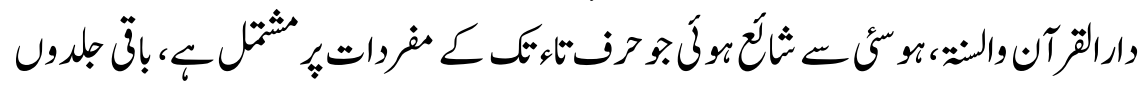

كُكامجاركب-

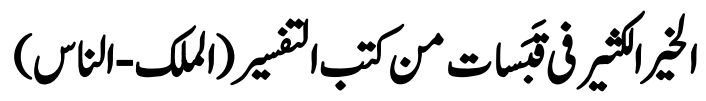

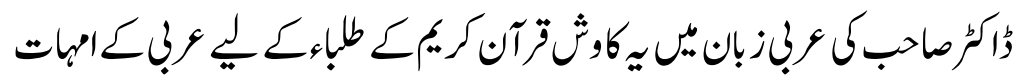

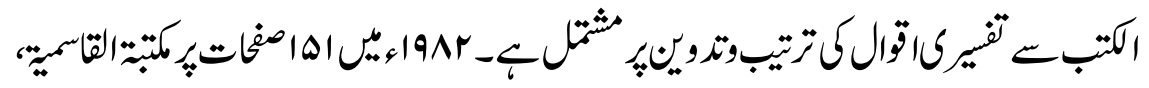

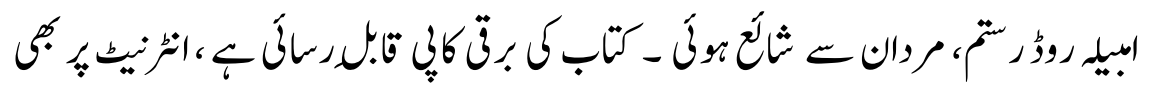

$$
\text { - }
$$

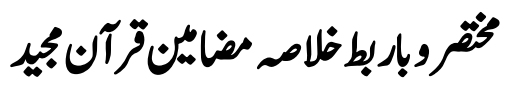

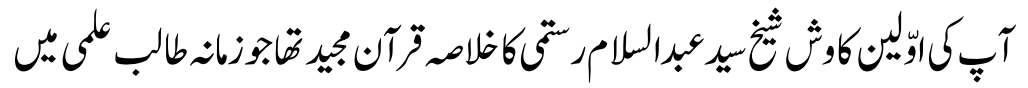

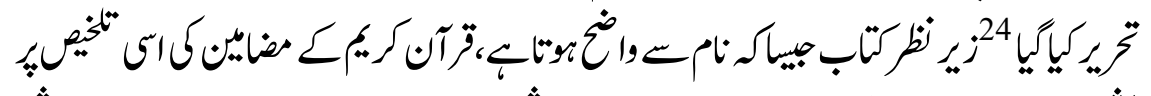

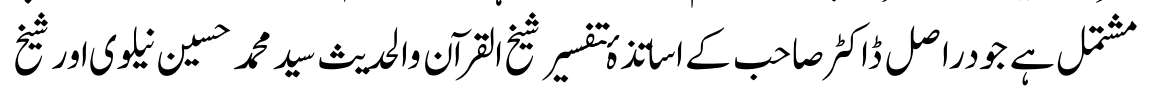

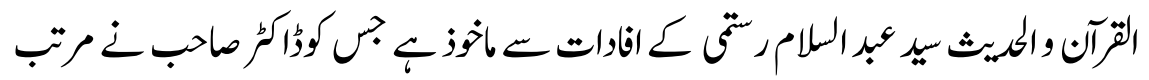

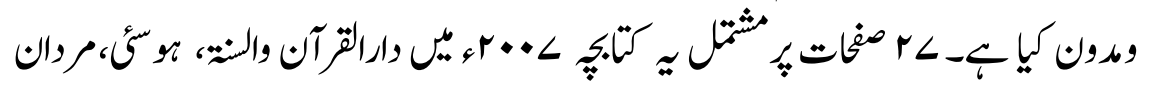

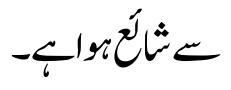

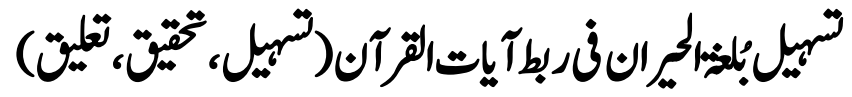

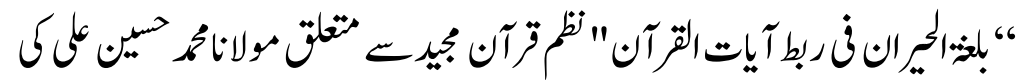

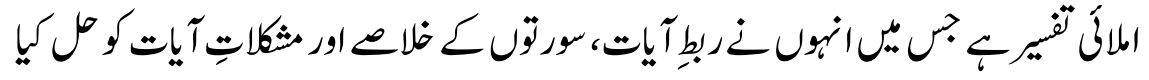




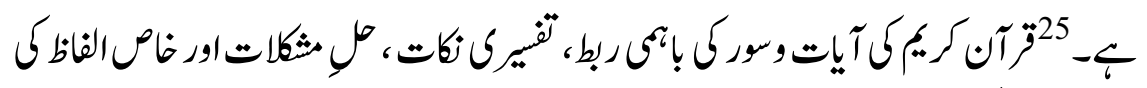

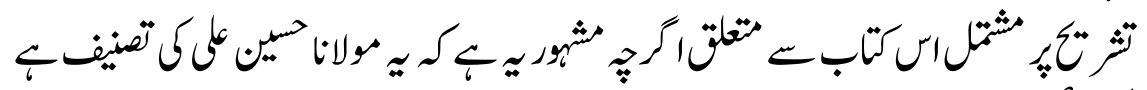

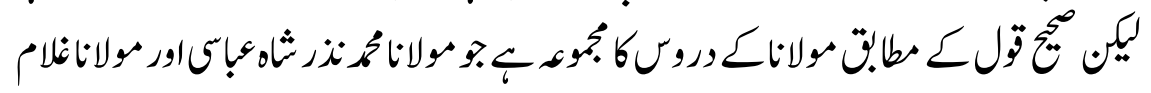

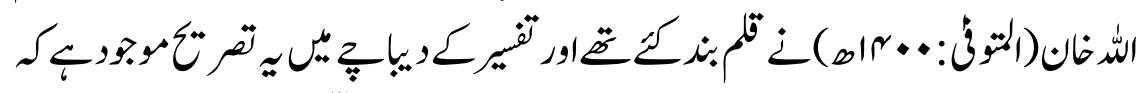

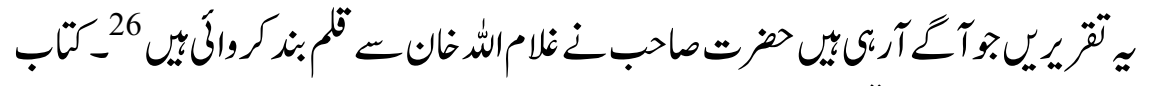

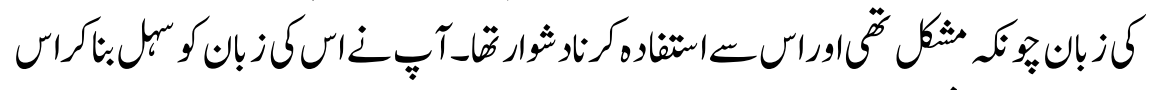

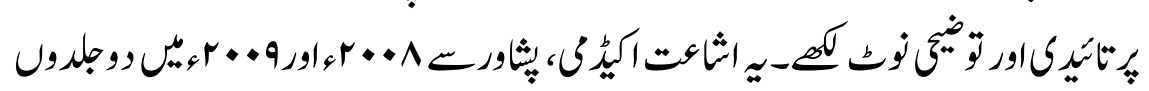

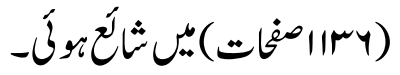

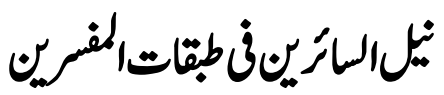

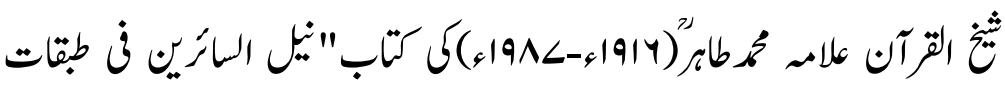

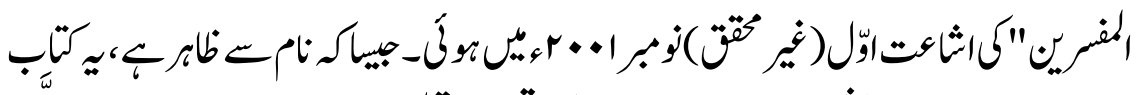

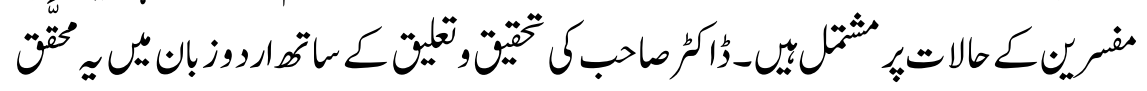

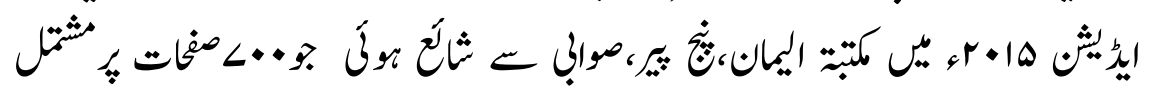

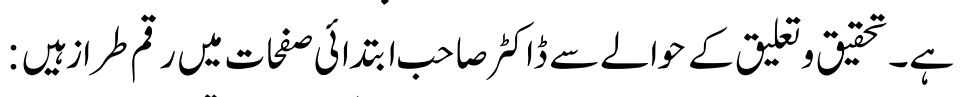

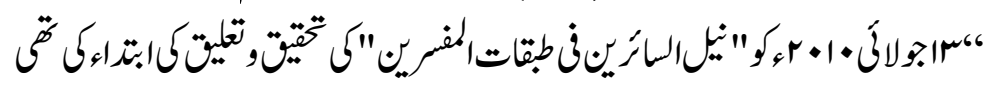

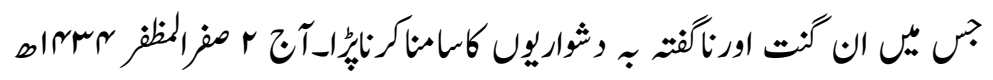
=

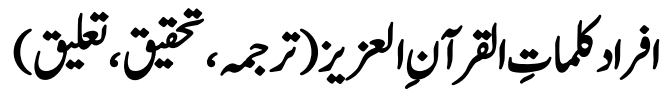

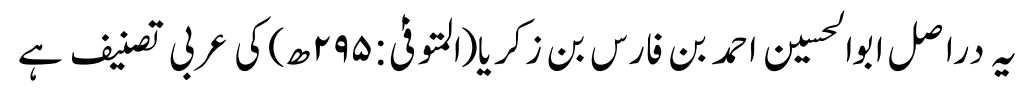

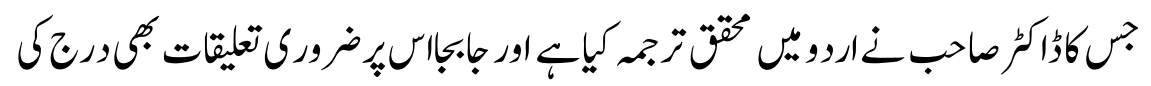

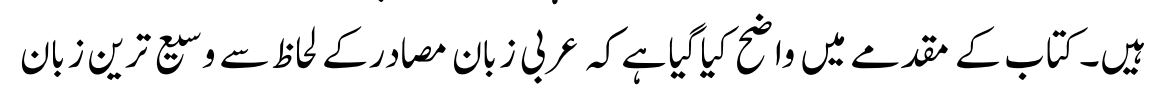




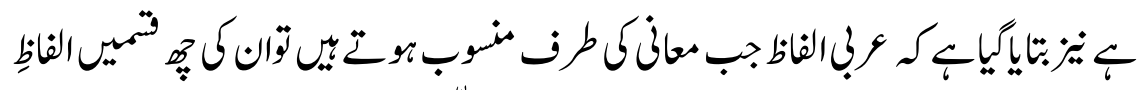

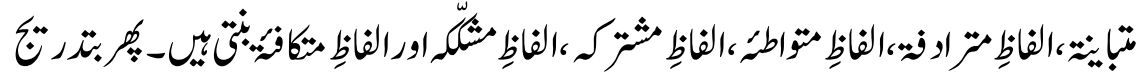

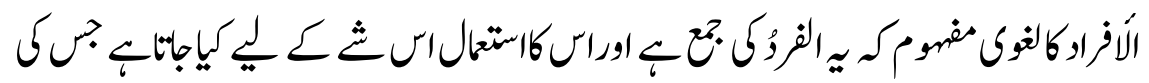

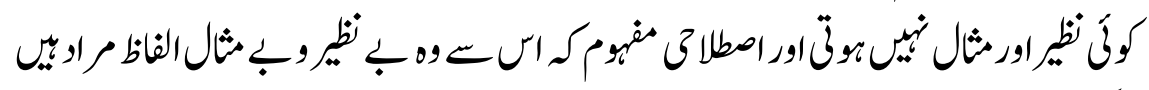

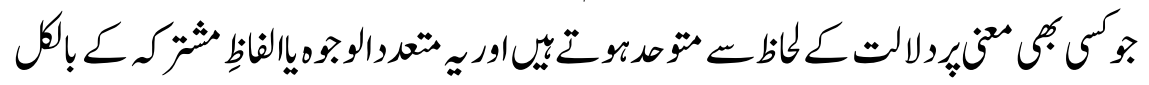

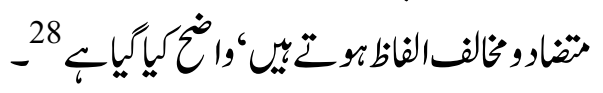

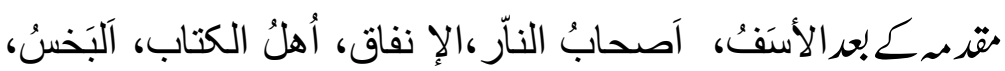

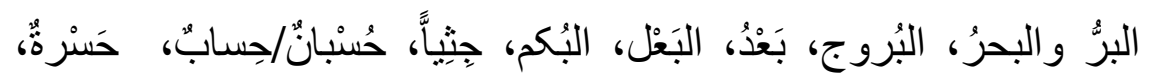

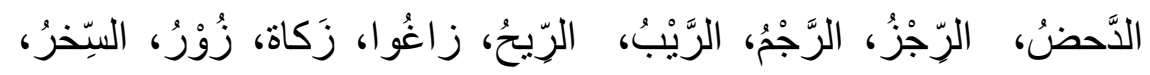

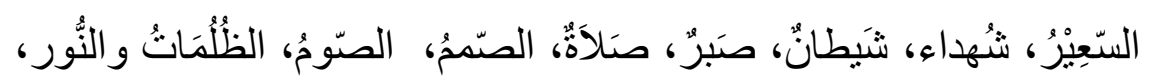

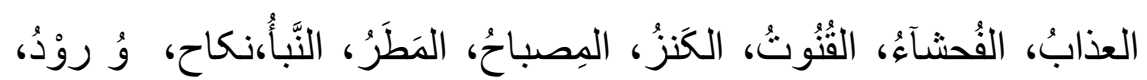

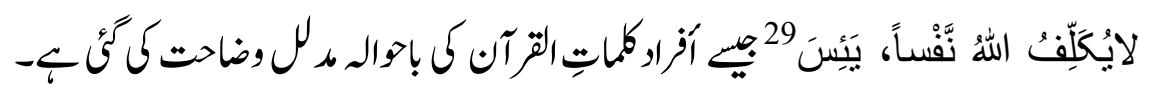

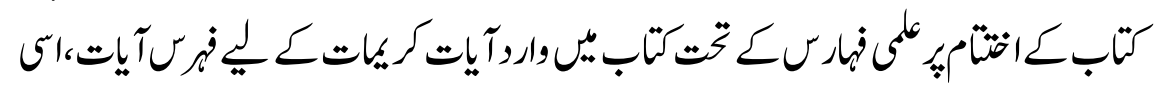

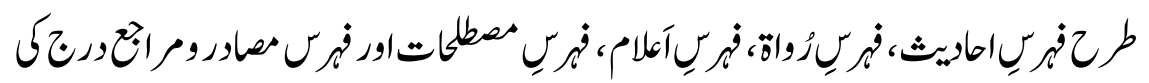

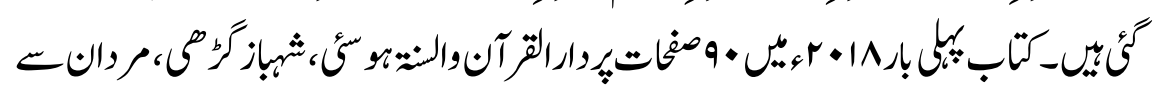

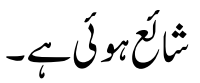

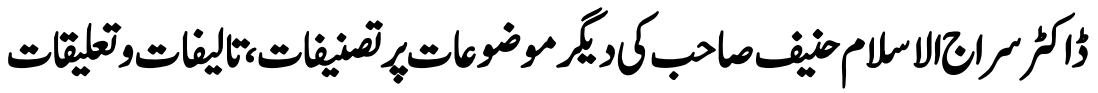

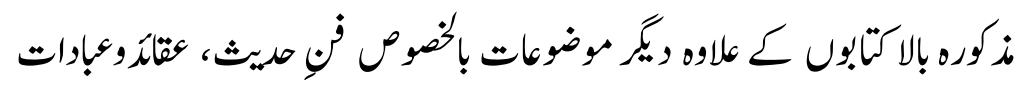

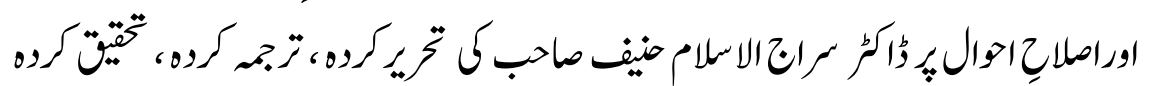

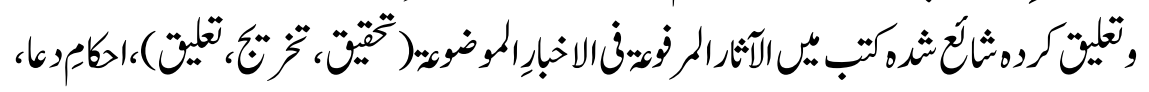

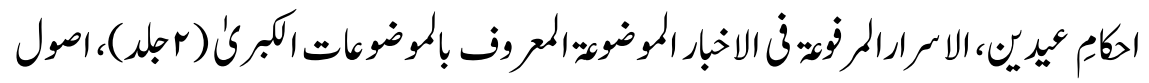

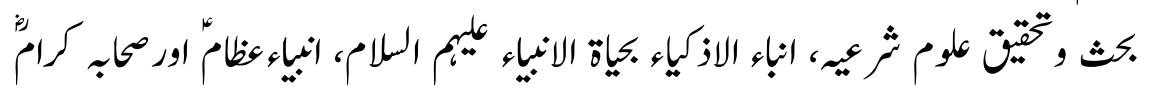




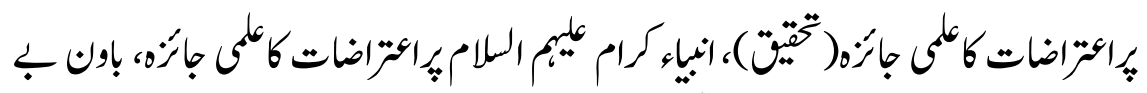

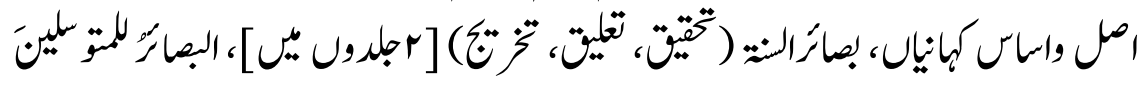

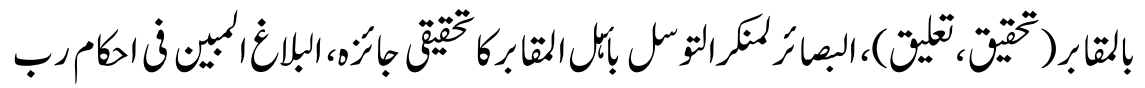

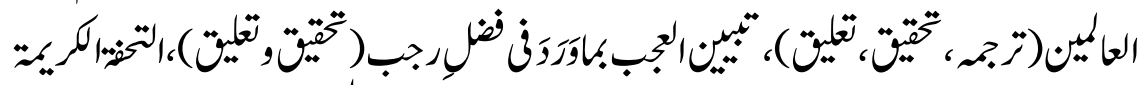

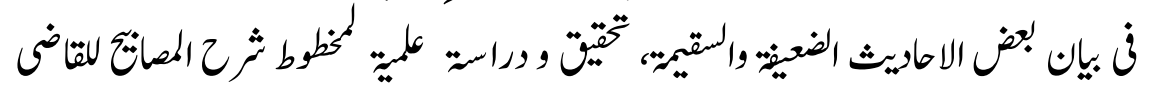

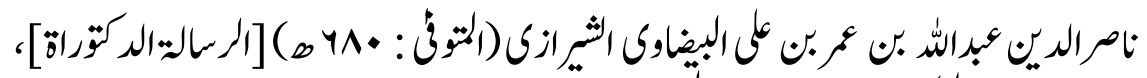

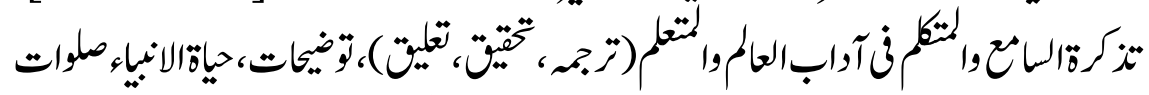

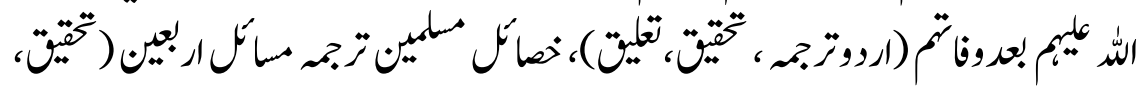

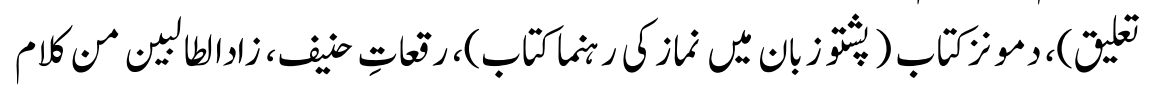

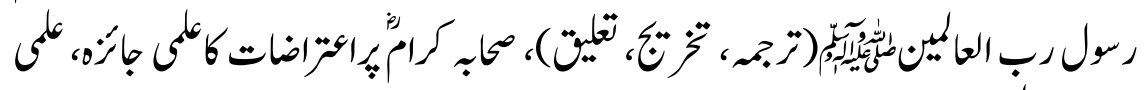

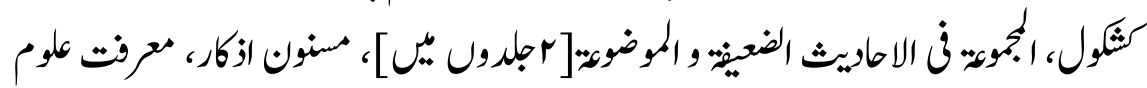

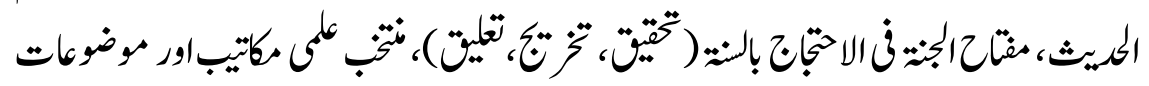

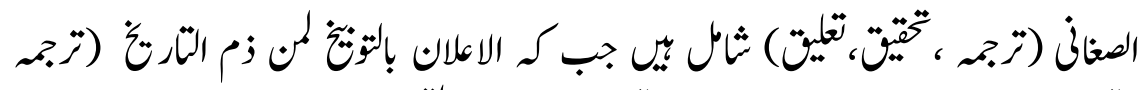

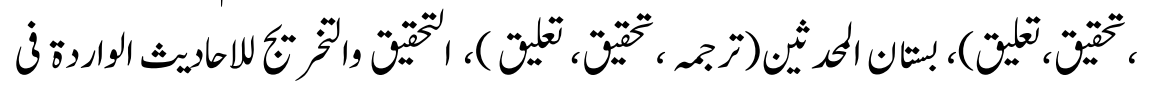

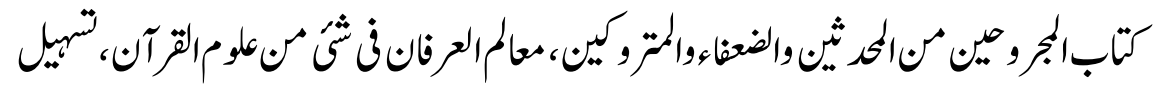

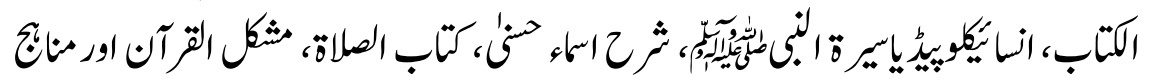

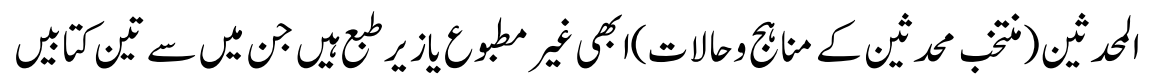

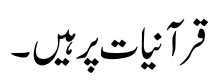

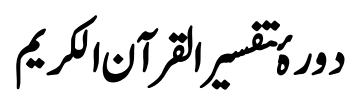

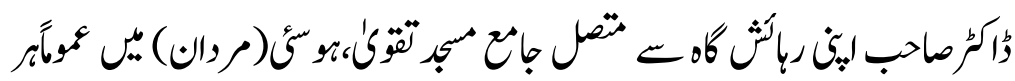

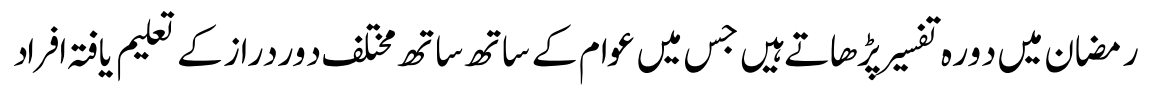

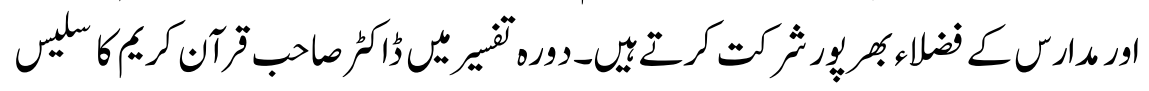




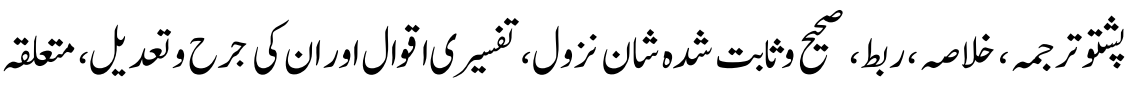

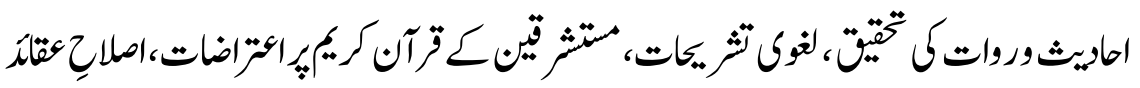

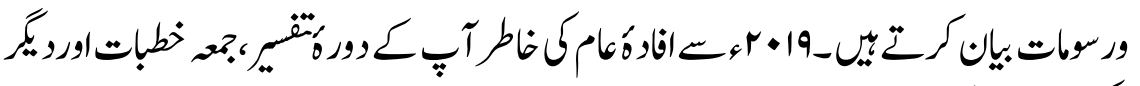

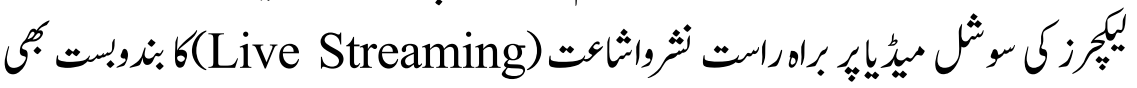

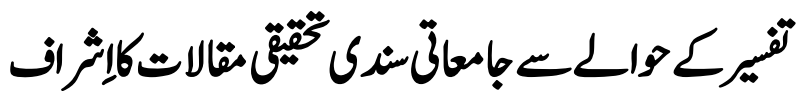

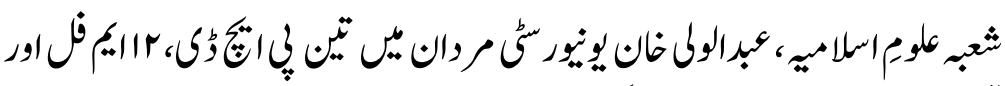

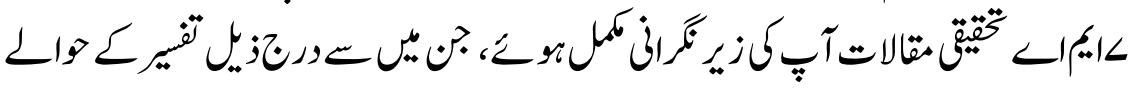
كب:

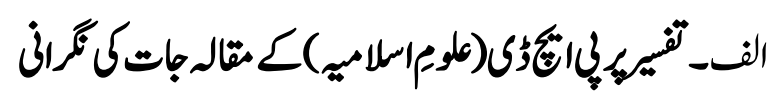

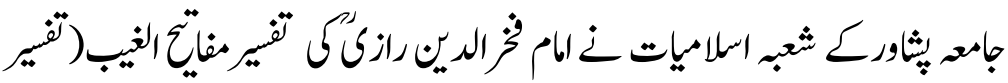

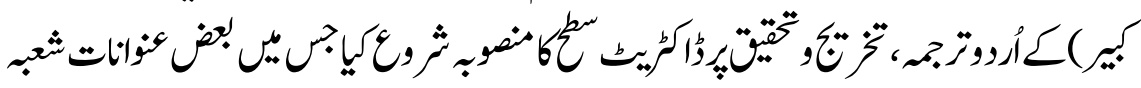

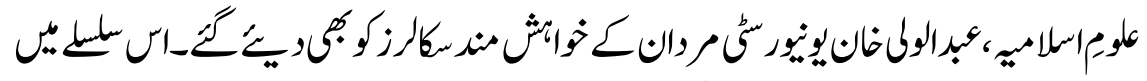

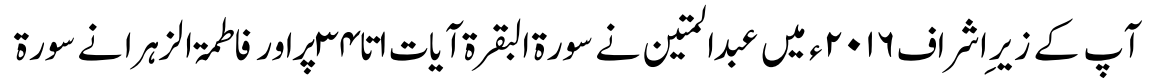

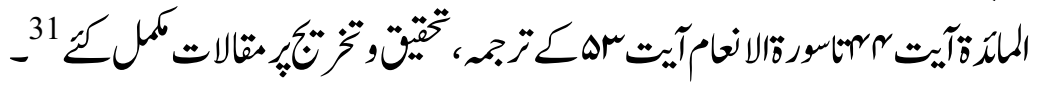

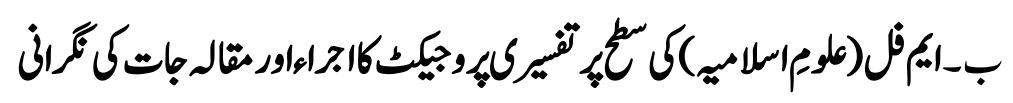

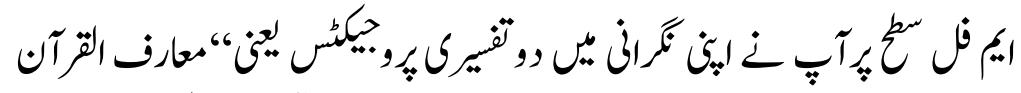

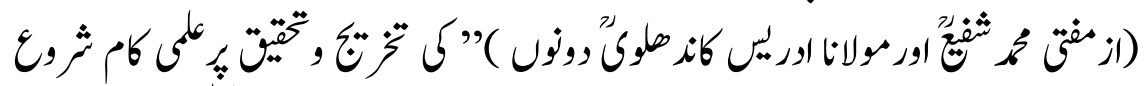

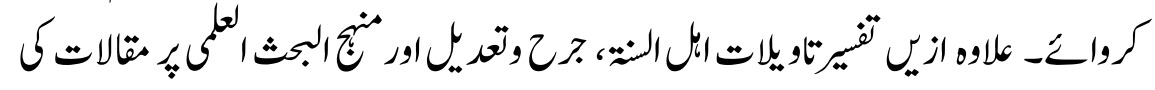




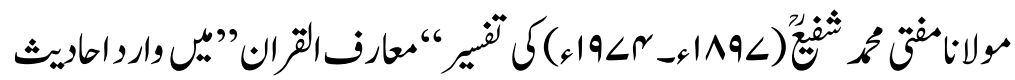

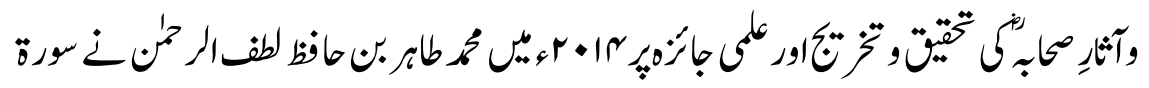

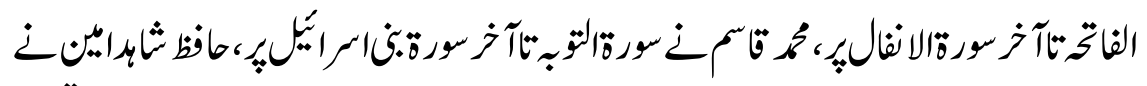

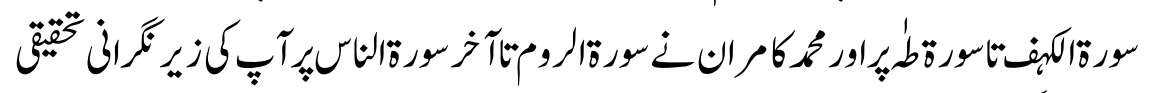
مقالات كمل كبك-

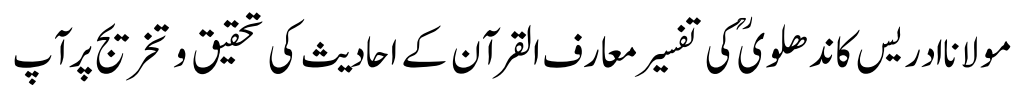

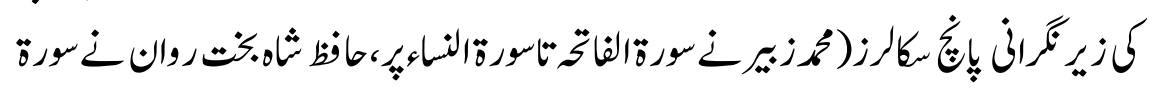

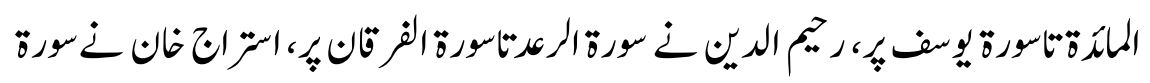

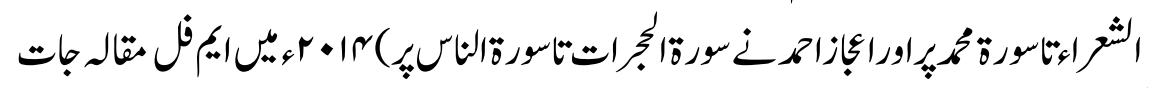

$$
\text { كمل كمي }
$$

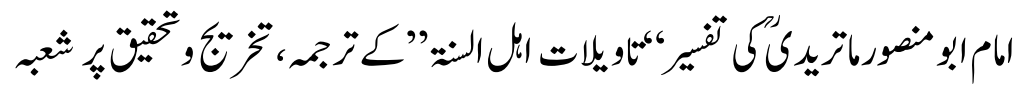

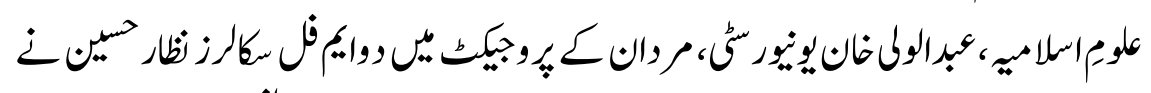

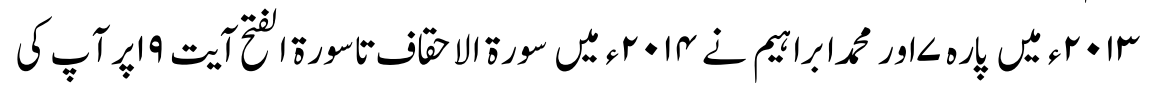

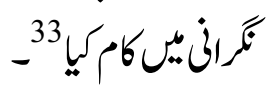

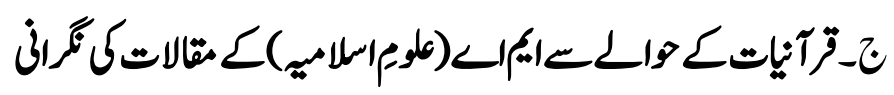

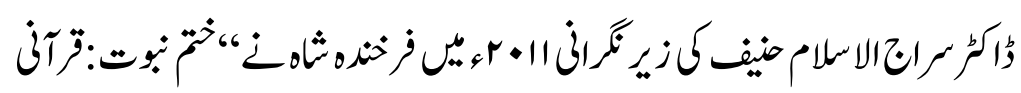

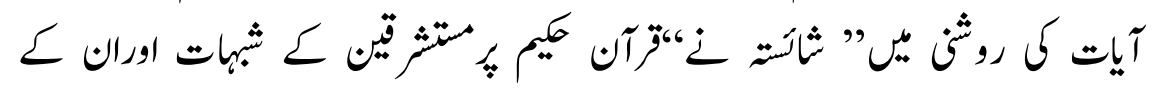

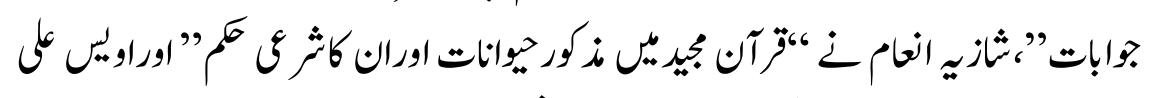

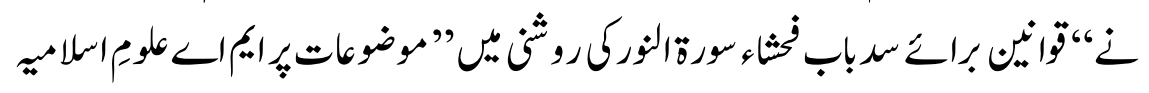

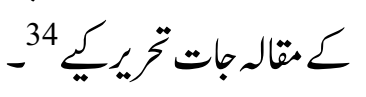

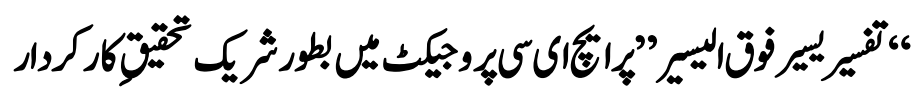




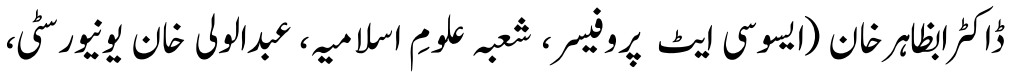

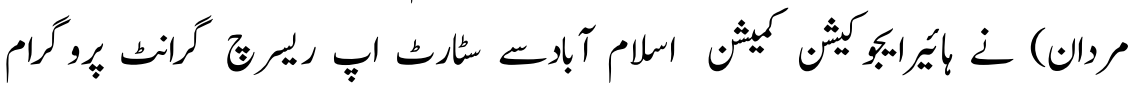

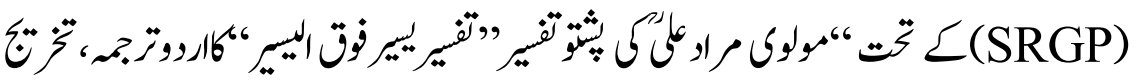

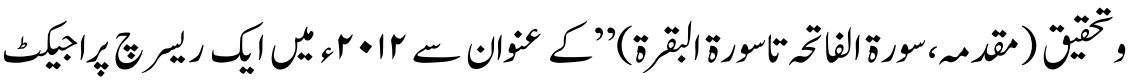

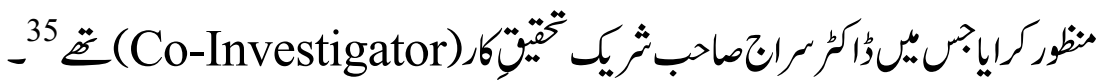

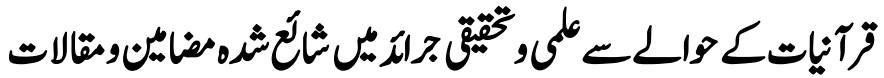

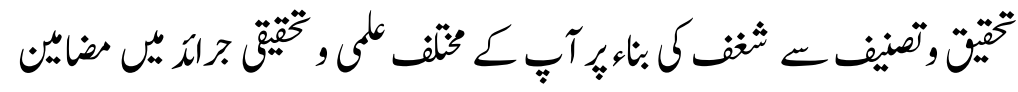

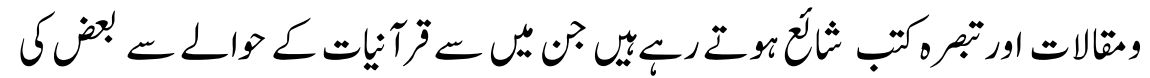

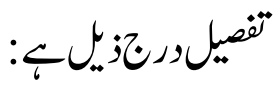

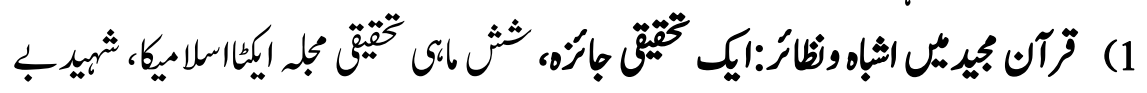

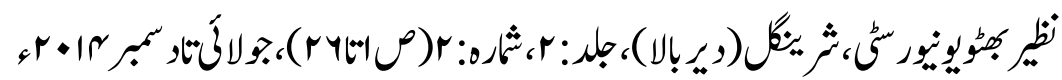
2)

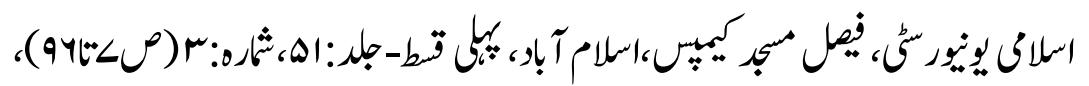

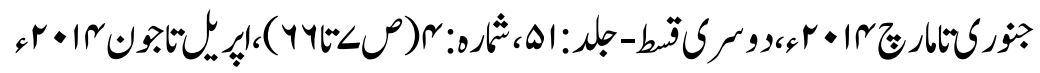

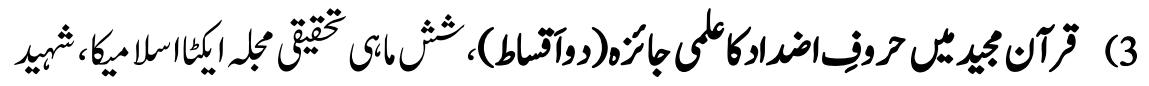

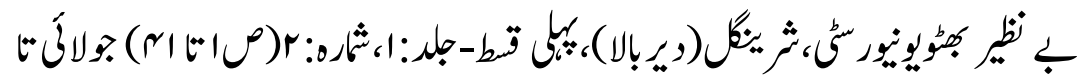

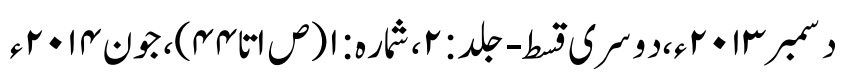

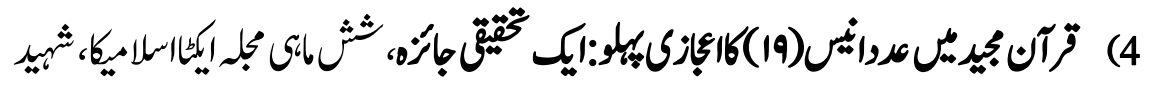

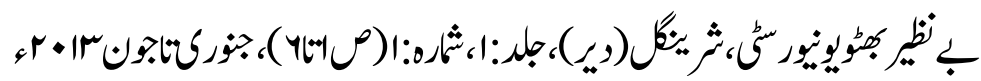

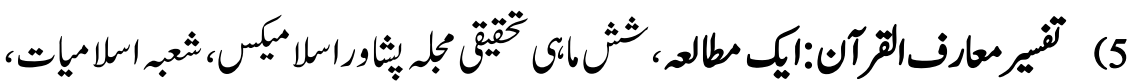

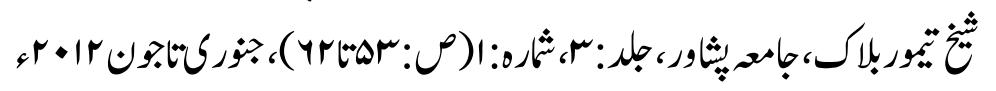




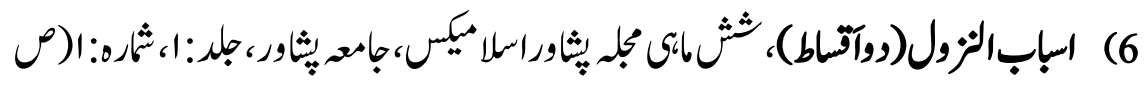

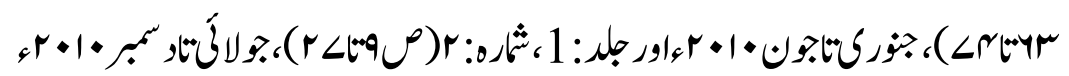




\section{ثلاص.كث}

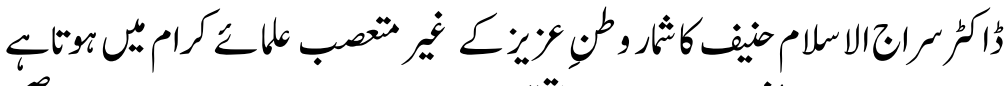

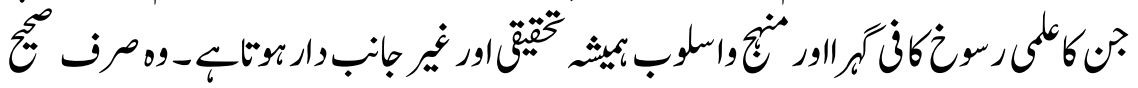

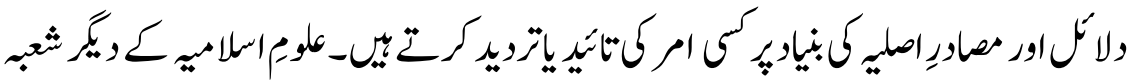

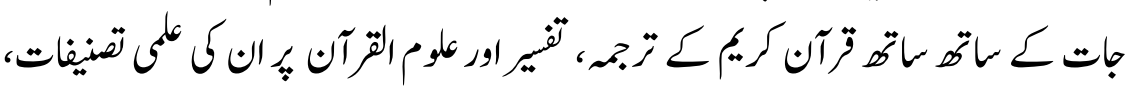

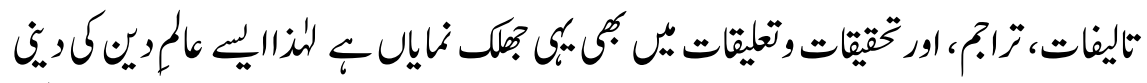

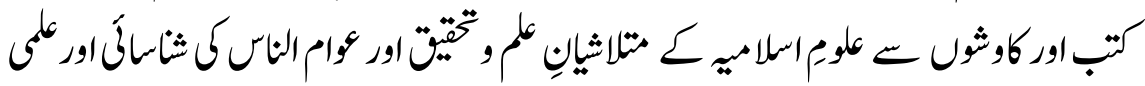

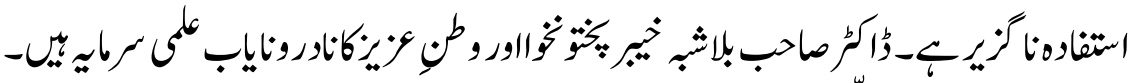

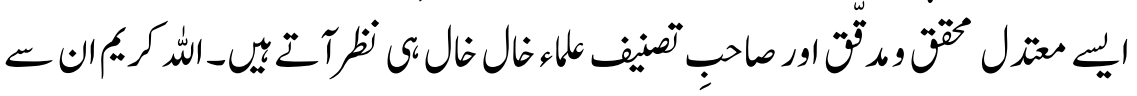

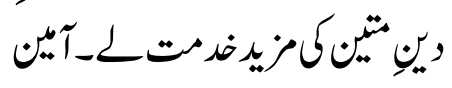

سفارثات

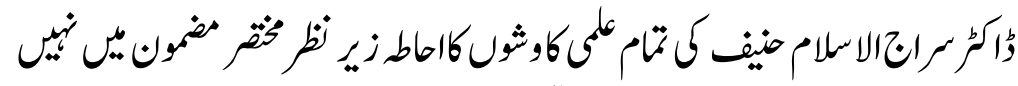

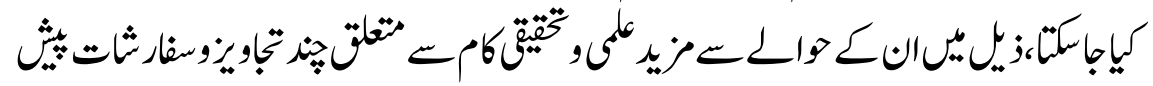
كمجارنكي":

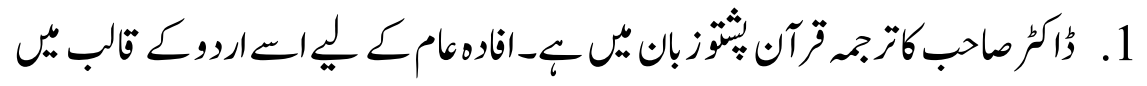

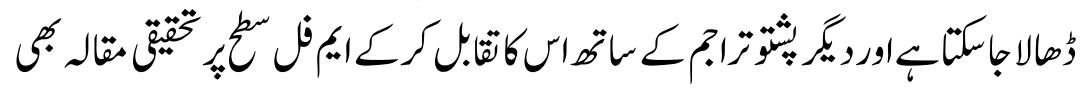
كلماجاسكتماك-

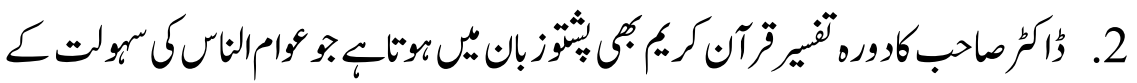

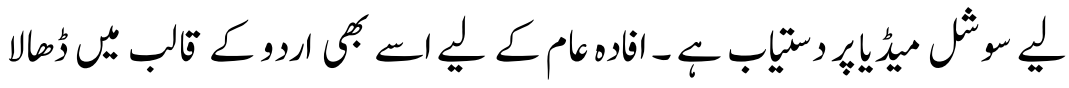

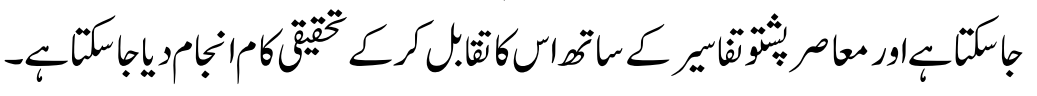




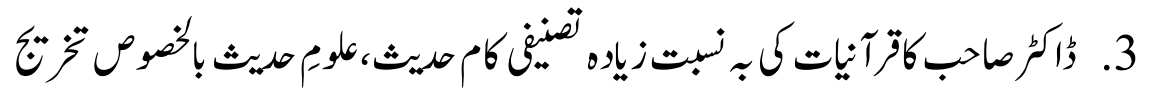

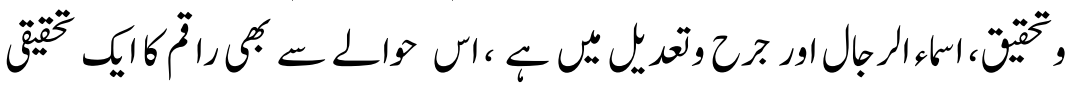

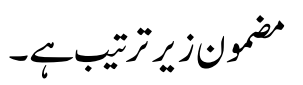

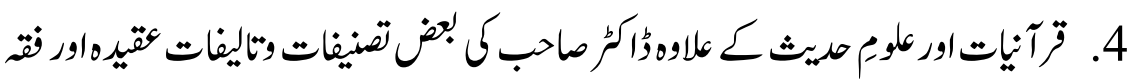

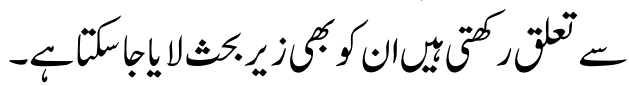

\section{هاشُّوحالح جإ/مصاورومرانح}

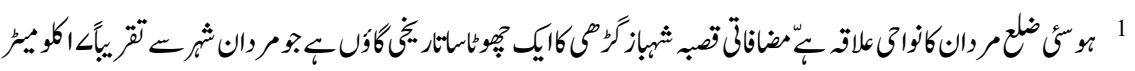

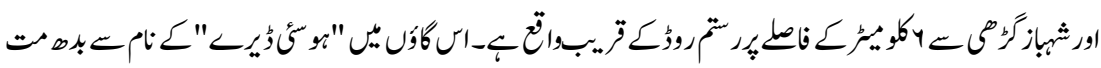

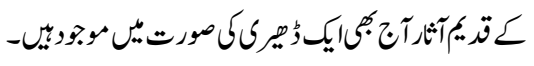

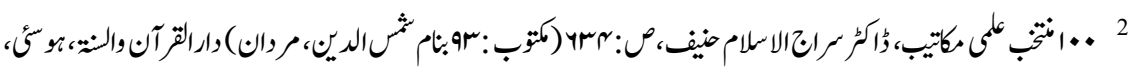

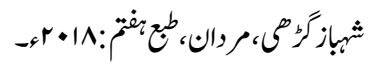

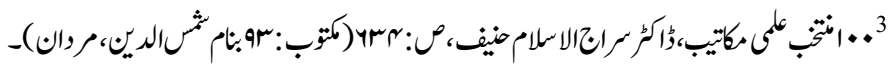

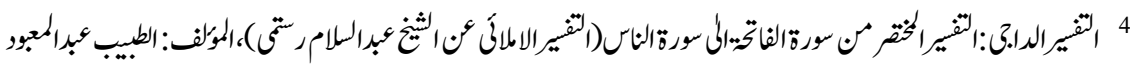

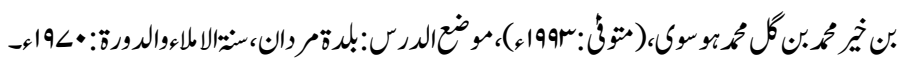

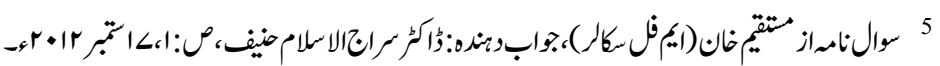
${ }^{6}$ https://www.alukah.net/library/0/120727/

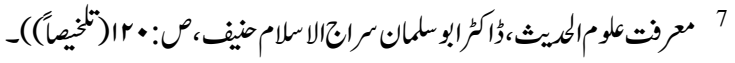

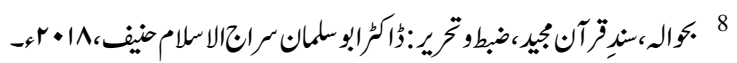

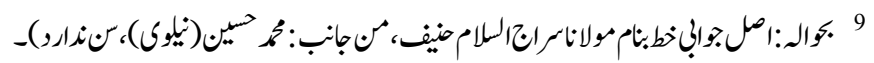

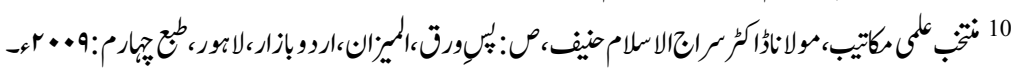

$$
\text { 11 }
$$

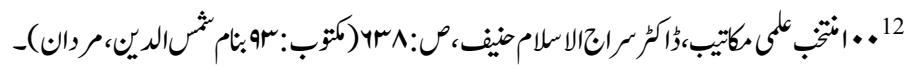

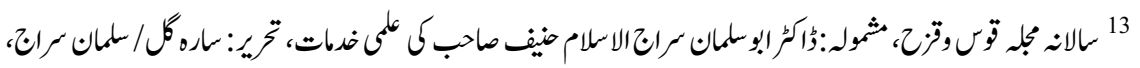

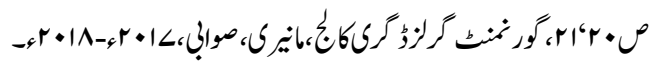

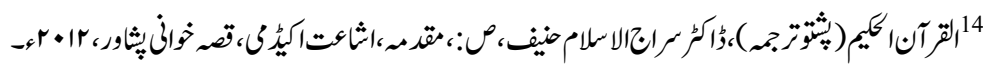




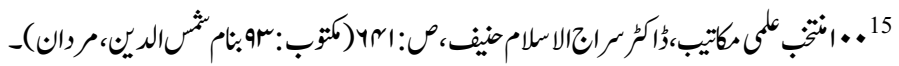

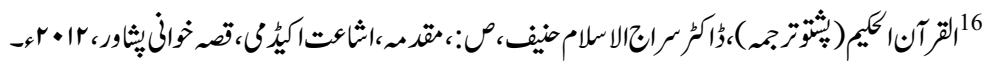

${ }^{17}$ www.kitabosunnat.com

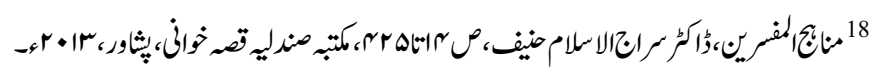

${ }^{19}$ https://www.scribd.com/document/366189829/Manahij-ul-Mufaserrien-by-Dr-Siraj-ulislam AND https://archive.org/download/ManahijUlMufaserrien/Manahij $\% 20 u 1 \% 20$ mufaserrien.pdf

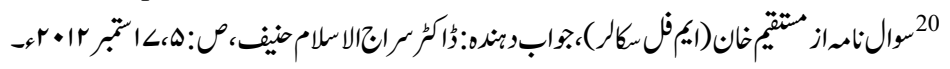

${ }^{21}$ http://www.alukah.net/sharia/0/120612/

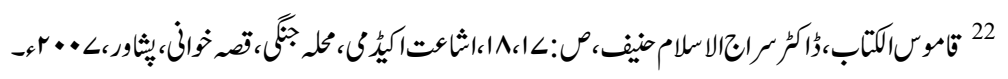

${ }^{23}$ https://www.scribd.com/document/370859978/Al-Khair-Ul-Kaseer-Al-Mulk-Ta-AlNaas-by-Dr-Siraj-ul-islam-hanief AND https://archive.org/download/AlKhairUlKaseerAlMulkTaAlNaas/al\%20khair\%20ul\%2 0kaseer\%20al\%20mulk\%20ta\%20al\%20naas.pdf

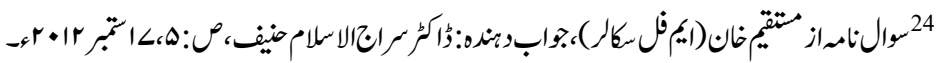

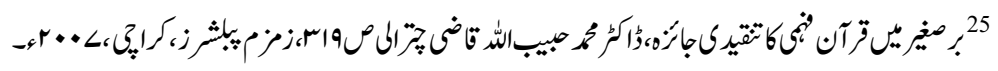

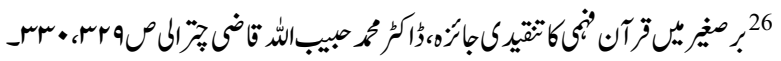

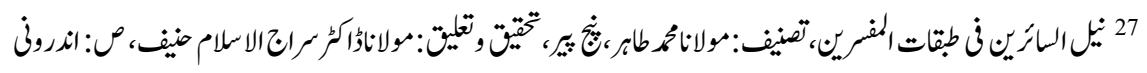

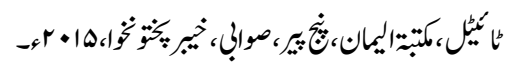

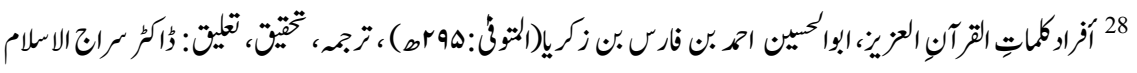

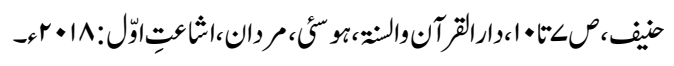

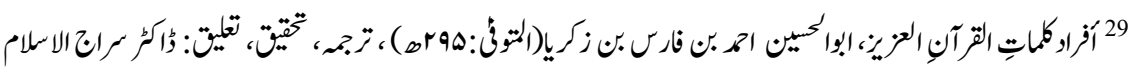

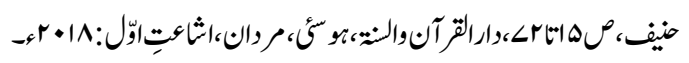

${ }^{30}$ https://web.facebook.com/sirajulislamhanief/videos/757279827759921/

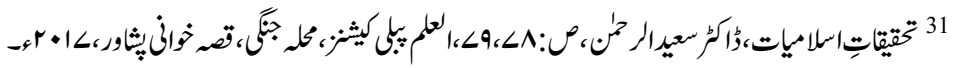

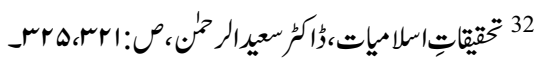

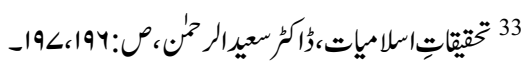

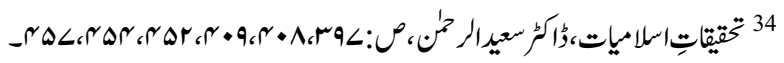

${ }^{35}$ Research Project Summary Sheet (SRGP), Dr Abzahir Khan, PP: 1, 2012 